\title{
The effect of climate and water resources on
}

\section{growing wheat and barley crops in the Najaf}

\section{governorate}

\author{
Lecturer Doctor. Hassan Abdullah $\quad$ Lecturer Doctor. Mustafa Kamil Othman $\quad$ Lecturer Iman Abdel-Hussein Shaalan \\ College of Education - University of Kufa \\ College of Arts - University of Kufa College of Arts - University of Kufa \\ hassana.alkaabi@uokufa.edu.iq \\ muslafa.alchalabi@uokufa.edu.iq \\ Iman.alattabi@uokufa.edu.iq \\ T; 07801790146 \\ T; 07825559082 \\ T; 07807175054
}

\begin{abstract}
;
Wheat is considered one of the basic foodstuffs, as it is the main material in the manufacture of loaves of bread and pastries. It comes second to humans after rice in its nutritional importance in several places of the world (including Iraq and including the study area), and its nutritional value is derived from its containment of starchy and nitrogenous material. The same applies to barley, which is one of the most important crops in the world, as it is ranked third in the world in terms of economic importance after rice and corn. The research came with five topics, the first was a theoretical framework, the second dealt with the natural characteristics of the study area, and the third discussed the effect of climate on the cultivation of wheat and barley crops, while the fourth topic dealt with the effect of water resources on growing wheat and barley crops, and the fifth topic came to shed light on the distribution Geography of wheat and barley crops in the province of Najaf. The research concluded a set of conclusions, including the effect of wheat and barley crops on the natural factors represented by the surface and climate elements, as we note the impact of these factors on the productivity of crops. We notice in the fourth topic the fluctuation of incoming water to the study area, which in turn led to fluctuation of production in some cultivated areas. It appears from the study of the geographical distribution of wheat crop in the study area that the Qadisiyah district occupied the first rank in wheat production for the year of study, while the freedom region ranked last for the production of this crop. From the study of the geographical distribution of the barley crop in the study area, it is clear that the Najaf District Center occupied the first rank for barley production, while Al-Huriya and Al-Abbasia districts occupied the last centers for barley production.
\end{abstract}

Key words: Climate, water resources, Growing wheat and barley. 


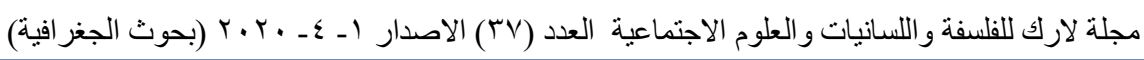

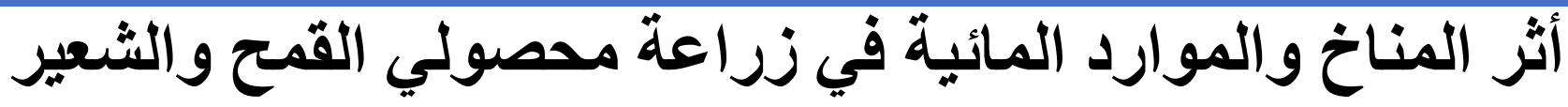 \\ في محافظة النجف الاشرف}

\author{
م. ايمان عبد الحسين شعلان \\ كلية الآداب-جامعة الكوفة
}

م.د. مصطقى كامل عثمان

كلية الآداب-جامعة الكوفة
م. د. حسن عبد الله

كلية التربية -جامعة الكوفة

الملخص

يعد القمح من المواد الغذائية الاساسية , كونه المادة الاساس في صناعة رغيف الخبز و المعجنات و ياتي في المرتبة الثانية للانسان بعد الرز في اهميته الغذائية في اماكن متعددة من العالم(منها العراق وبضمنه منطقة الدراسة) , وقيمته الغذائية متأتية من احتو ائه للمادة النشوية والآزوتية ـ. كذللك الحال بالنسبة لمحصول الثعير الذي يعد من المحاصيل الهامة في العالم إذ يأتي في المرتبة الثالثة عالميا من حيث الأهمية الاقتصادية بعد الأرز والذرة ـ وجاء البحث بخمس مباحث , كان الاول عبارة عن اطار الهاري نظريا , اما الثاني فتناول الخصائص الطبيعية لمنطقة الدراسة , وناقش الثالث اثر المناخ في زر اعة محصولي القمح والثعير , اما المبحث الر ابع فتناول اثر الموارد المائية في زراعة محصولي القمح و الثعبير, وجاء المبحث الخامس ليلقي الضوء على التوزيع الجغر افي لانتاج محصولي القمح و الشعير في محافظة النجف الاشرف ـ وخلص البحث الى مجموعة من الاستتناجات منها ناتثر انتاج محصولي القمح والثعير بالعوامل الطبيعية المنمثلة بالسطح وعناصر المناخ , اذ نلاحظ ناثير تللك العوامل على انتاجية

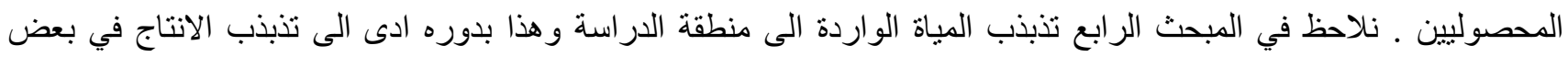
المناطق المزروعة ـ يظهر من دراسة التوزيع الجغر افي لمحصول القمح في منطقة الدراسة ان ناحية القادية احتلت المرتبة الاولى في انتاج القمح لسنة الدر اسة فيما احتلت ناحية الحرية المرتبة الاخيرة لانتاج هذا المحصول ـ يتبين من دراسة التوزيع الجغرافي لمحصول الثعير في منطقة الدراسة , ان مركز قضاء النجف احتل المرتبة الاولى لانتاج الشعير فيما احتلت ناحيتي الحرية و لهاج العباسية المر اكز الاخيرة لانتاج الشعير. كلمات مفتاحية : المناخ، الموارد المائية، زر اعة القمح و الثعير. (www.reefnet.gov.sy. الحاجة إلى القمح سنويا وهذا يقود الى السعي باسنمرار الى لى تطوير وتتمية زراعته للحفاظ على التوازن ما بين الناتج الكلي والطلب عليه من خلال استخدام الأساليب العلمية الحديثة والمبتكرة لتطوير زراعة هذا المحصول وتنميته واستغلال المتوفر من الإمكانيات و الوسائل بالثكل الأمثل من ون الأرض و المياه و البذر و المخصبات والاسمدة والمبيدات

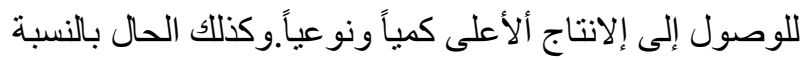

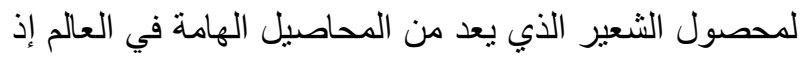
يأتي في المرتبة الثالثة عالميا من حيث الأهمية الاقتصادية

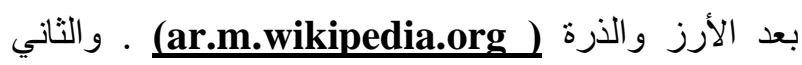
محليا من حيث اهميته في المائدة العراقية ، وقد عرف هذا المحصول في العالم القديم في عصور ما قبل التاريخ اذ

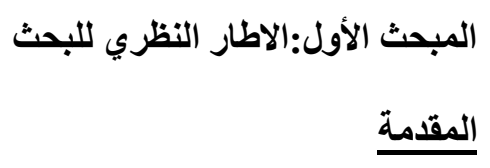

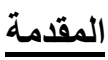

القمح من الموادالغذائية الاساسية, كونه المادة الاساس في صناعة رغيف الخبز و المعجنات وياتي في المرتبة الثانية للانسان بعد الرز في اهميته الغذائية في اماكن متعددة من العالم(منها العراق وبضمنه منطقة الدر اسة) , وقيمته الغذائية متأتية من احتوائه للمادة النشوية والآزوتية (البزازي

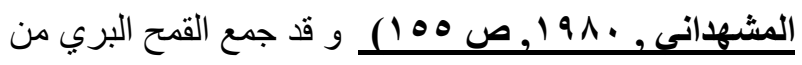
قبل الانسان قبل بداية الزراعة بزمن طويل ويعتقد العلماء

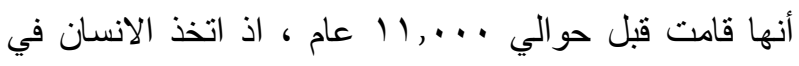
منطقة الثرق الأوسط أولى خطواته باتجاه الزراعة، وكان

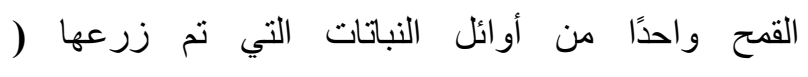


استخدمه الإنسان كغذاء. ولازال يستخدم في بعض مناطق

العالم مثل هضبة التبت كوجبة أساسية للإنسان ــ وترتبط

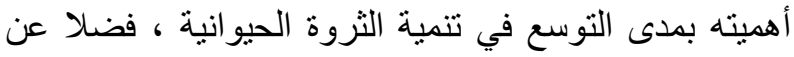
استعماله في الصناعات الغذائية وفي صناعة بعض لئ الأدوية.

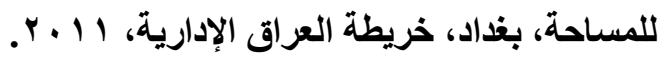

إمشكثة البحث:

هـ موعد زراعة وحصاد محصولي القمح والثعير* :

يبدا موعد زراعة القمح في منتصف شهر تشرين ثان

لذللك وجب التبكير في البذار وتقسيم الحقل الى الواح ليصبح بالمستطاع سقي الحقل من الناحيتين العملية والنطبيقية في المدة المحصورة بين(10_0 ب)تشرين ثان ولا يجوز التأخر عن ذللك ضمانا للحصول على الانتاج العالي ، و عند حدوث معوقات تحول دون امكانية تنفيذ سقية الانبات ضمن المدة المحددة اعلاه ،عند ذلك يخطط أساسا للتنفيذ في المدة المحصورة بين (0_0)تشرين ثان او بين (0 (10 • ب)تشرين ثان او حتى بين ( ا • ب)تشرين ثان و لابد من الاشارة هنا الى لى ان موعد اول سقية تسمى بسقية الانبات, اذ يعد موعد لردئ الزر اعة عاملا حيو يا ومفتاحا للحصول على انتاج و افر وكلما تأخر موعد الزراعة انخفض الانتاج مهما كانت الدقة في تتفيذ جميع قواعد التكنولوجيا الزراعية السابقة لموعد الزراعة واللاحقة به ضمن المنطقة الاروائية كما في منطقة البحث , اذ يبدا مو عد حصاد القمح عندما يصل الى مرحلة النضج الملائمة المطلوبة كما ونوعا اي بعد نضجها الكامل مباشرة وذللك بطريقتين يدويا بالمنجل و اليا باستخدام الحاصدة الدراسة ( الكمباين) حتى تبدأ عملية الحصاد وعد م تأخيره لان ذلك يؤدي الى خسارة في الحاصل تزداد يوماً بعد يوم , و لإجراء عملية حصاد القمح بشكل ناجح ينصح باستخدام ماكنة (الحصادة الدراسة ) بعد النضج مباثرة لتجنب مشكلة

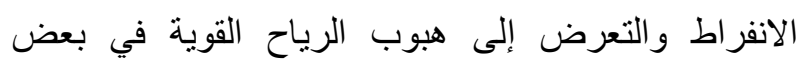
المو اسم مؤدية إلى الانفراط المفاجئ في بعض انواع القمح .

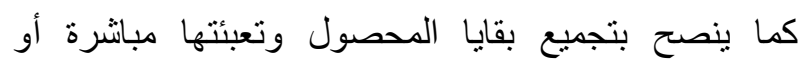
معاملتها باليوريا و الاستفادة منها في تغذية الحيو انات كعلائق مركزة ـ و الابتعاد عن حرق بقايا المحصول قدر الإمكان لأن عملية الحرق تؤدي إلى فقدان المادة العضوية من التربة وتقضي على البكتيريا المفيدة الموجودة فيها. اما بالنسبة 3 لمحصول الشعير فيبدأ موعد زراعته خلال شهر تشرين ما اثر المناخ والموارد المائية في زر اعة وانتاج محصولي القمح و الثعير في محافظة النجف الاشرف؟

برضية البحث:

يفترض الباحثون ان للمناخ والمو ارد المائية اثرا كميا ونوعيا كبيرا في زر اعة وانتاج محصولي القمح والثعير في محافظة النجف الاشرف.

\section{بــدف البحث:}

يهدف البحث الى تسليط الضوء على اثر المناخ والموارد المائية ومدى ملائمتها لزراعة وإنتاج محصولي القمح و الثُعير في محافظة النجف الاشرف .

\section{ع ـحدود منطقة الدر اسة :}

تتمنل منطقة الدراسة في محافظة النجف التي تقع في الجزء الجنوبي الغربي من العراق وتتحصر رقعتها

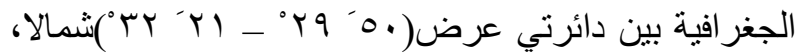

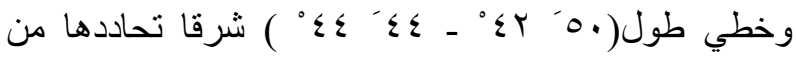
الثمال محافظتي بابل وكربلاء ومن الشرق محافظتي القادسية والمثنى ، في حين تحدها المملكة العربية السعودية من الجنوب الغربي ومحافظة الانبار من الغرب خريطة (1).

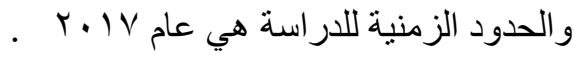
خريطة ( ) موقع محافظة النجف من العراق

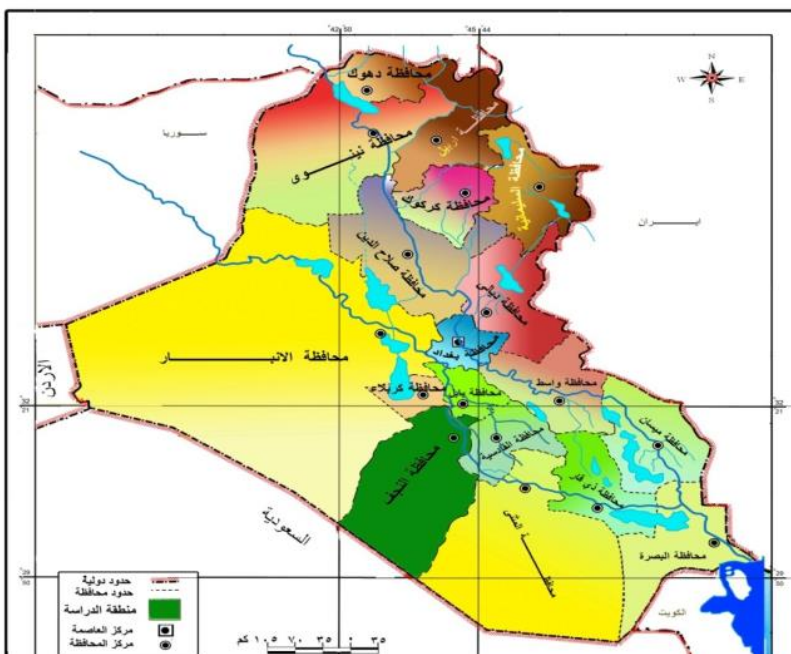




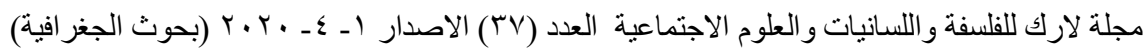

تستطيع الدولة عن طريق مخازنها من استلامه لتامين مفردات البطاقة التموينية (الطحين) بالنسبة لمحصول القمح تحديدا فضلا عن الاسواق في محافظة النجف و المحافظات الاخرى .للموقع بالنسبة إلى دوائر العرض الأثر الواضح في تحديد كمية الإشعاع الشمسي الواصل ومدى شدة ذلك الإشعاع اللذان يحددان طبيعة الخصائص الحرارية خصوصا والخصائص المناخية بشكل عام لمنطقة الدراسة التي

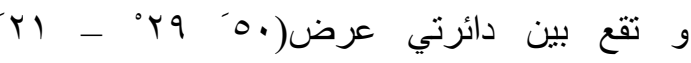

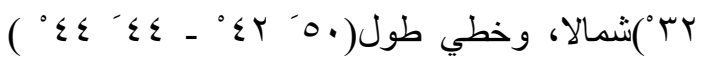
شرقا , وبناءا على ماتقدم اذ تتحكم زاوية الإشعاع الثمسي و طول فترة النهار في كمية الإشعاع الشمسي الواصلة لمنطقة الدراسة اذ ان طول فنرة النهار تتباين من شهر لأخر. ففي شهر أيلول نرى إن طول النهار يقصر بشكل كبير , وتقل كمية الإشعاع الثمسي الواصل إلى منطقة الدراسة , إما في شهر كانون الأول فيكون طول النهار اقصر مما بكون عليه مقارنة مع بقية أثهر السنة ليصل إلى (• ( ) ساعات ثم يزداد حتى يصل في شهر آذار إلى (1 (1) ساعة

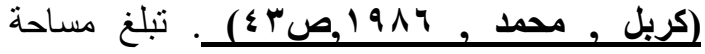

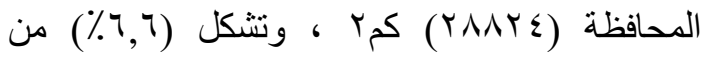

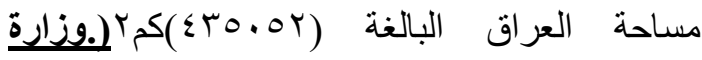
التخطيط والانماء , الجهاز المركزي للاحصاء وتكنولوجيا المعلومات المجموعة|لاحصائية

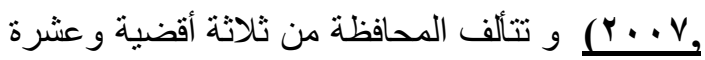
وحدات ادارية متباينة في مساحتها جدول (1) خريطة
الثاني في المناطق الاروائية (كما في منطقة البحث) ويحدد هذا الموعد بتاريخ الرية الاولى (رية الانبات) , كما يزرع الشعير مبكرا في بعض الاحيان وحسب الحاجة من قبل العديد من المزارعين في بداية شهر تشرين الاول لأغراض العلف الاخضر ـ يحصد الثعير في المناطق الاروائية من العراق في النصف الاول من شهر مايس ومن الضروري تجنب تأخير الحصاد بعد هذا التاريخ لئلا يتعرض الحاصل الى الظروف الجوية غير المناسبة والى مهاجمة الطيور والى الانفر اط مما ينرتب عنه خسارة كبيرة في الانتاج و الطريقة السائدة بحصاده ودر استه وتنظيفه مرة واحدة أثناء النضج

$$
\text { الكامل للحبوب. }
$$

المبحث الثاني : الخصائص الطبيعية لمنطقة الاراسة: سيتم في هذا المبحث مناقشة الخصائص الطبيعة لمنطقة الدر اسة وسينفرد المبحثين الثالث والرابع لمناقثة اثر المناخ والموارد المائية في زراعة محصولي القمح والثعير في محافظة النجف الاشرف . أولا:الموقع والمساحة :ا - تتمثل منطقة الدراسة في محافظة النجف الاشرف التي تقع في الجزء الجنوبي الغربي من العراق, اذ تحدها من الثمال محافظتي بابل وكربلاء ومن الثرق محافظة القادسية ومن الجنوب الشرقي تحدها محافظة المثنى ، في حين تحدها المملكة العربية السعودية من الجنوب الغربي ومحافظة الانبار من الثمال الغربي وللموقع الجغرافي لمنطقة الدراسة الاثر الواضح. بارتباطها بأكبر سوق في العراق وهي محافظة بغداد والتي يمكن الوصول اليها عن طريق محافظة بابل وهذا بساعد على تسويق المحصولين عند التوسع في زراعتهما ووجود الفائض في الانتاج والذي لا

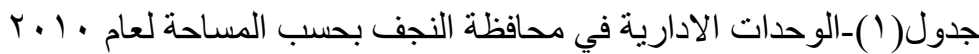

\begin{tabular}{|c|c|c|c|}
\hline الاهمية النسبية\% & المساحة(كمץY) & الناحية & القضاء \\
\hline$r, \otimes V$ & 1.49 & مركز قضاء النجف & النجف \\
\hline$\varepsilon, Y q$ & ITYA & & \\
\hline$\Lambda \wedge, I r$ & ros.. & الشبكة & \\
\hline
\end{tabular}




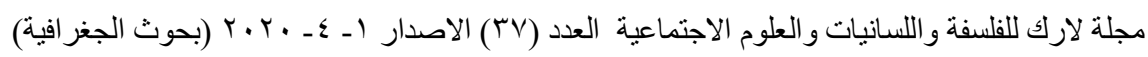

\begin{tabular}{|c|c|c|c|}
\hline \multicolumn{2}{|r|}{ YVY०V } & \multicolumn{2}{|r|}{ المجموع } \\
\hline r & 90 & مركز قضاء الكوفة & \multirow[t]{3}{*}{ لكوفة } \\
\hline Vq & $r Y \Lambda$ & العباسية & \\
\hline$r V$ & $1 . V$ & الحرية & \\
\hline \multicolumn{2}{|r|}{$\varepsilon r}$. & \multicolumn{2}{|r|}{ المجموع } \\
\hline$r Y$ & 94 & مركز قضاء المناذرة & \multirow[t]{4}{*}{ المناذرة } \\
\hline $9 r$ & YYO & الحيرة & \\
\hline$\varepsilon q$ & ITr & المشخاب & \\
\hline 97 & rVV & القادسية & \\
\hline \multicolumn{2}{|r|}{ VHV } & \multicolumn{2}{|r|}{ المجموع } \\
\hline$\% 1 \ldots$ & 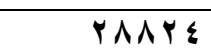 & \multicolumn{2}{|r|}{ مجموع مساحة المحافظة } \\
\hline
\end{tabular}

المصدر : علي مردان تايه الجبوري,الخصائص المناخية لمحافظة النجف الاشرف وعلاقتها بالافات الزراعية المؤثرة فياتتاج

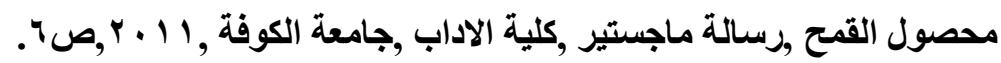

في حين يمر خط الارتفاع (10) مج في جهاته الجنوبية (الهيئة

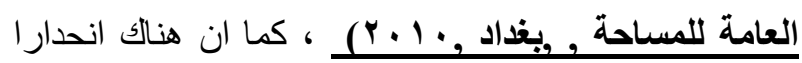
من مناطق كتوف الانهار وقنوات الري الى مناطق الاحو اض المجاورة لهذه الكتوف والتي تنخفض عنها بمعدل (r-r)م (Buring, 197،,p151) . يضم هذا القسم ايضاً عدد من الاهو ار و المستنقعات (ابن نجم ، و الطوك و الغز الي ،و الثامية ، وبحر النجف ، وصليب ) و التي تظهر في اقسامه الثمالية الثرقية و الجنوبية. والتي تم تجفيف معظمها منذ تسعينيات القرن الماضي وتم تغذية بعض أقسامها كما في هور ابن نجم ـ اما القسم الثاني فيتمثل بالهضبة الغربية الصحراوية و تتألف من منطقتي الوديان السفلى والحجارة وتبلغ مساحتها STVOY (Y )

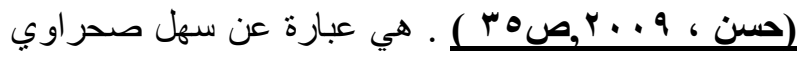
يمند من الجنوب الغربي نحو الثمال (Desert plain)

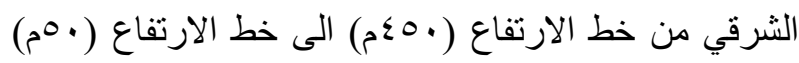

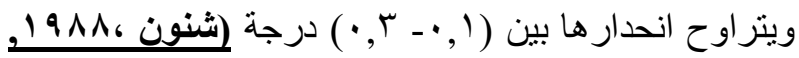
صهץ). وبالتالي فان سطح المحافظة ملائم لزراعة و لنمو المحاصيل الزر اعية باختلاف انو اعها ـ ومن بينها محصولي لئي القمح و الشعير , وان زر اعة محصولي القمح و الثعير تتطلب مناطق سهلية ذات انحدار تدريجي تساعد على تصريف مياه الري وتساعد على حراثة الأرض وتسويتها قبل زراعتها خريطة(r)_الوحدات الإدارية في محافظة النجف

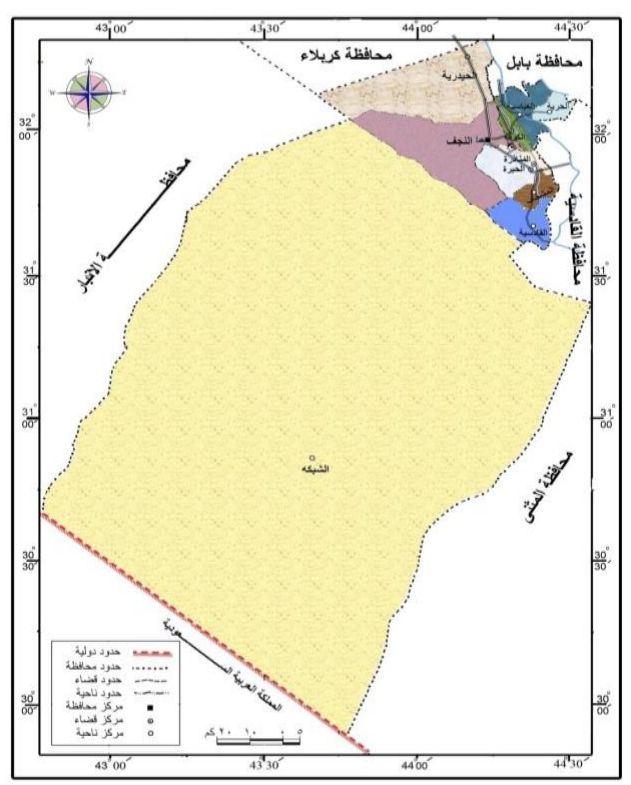

المصدر : مديرية زراعة النجف , قسم الاحصاء , اطلس

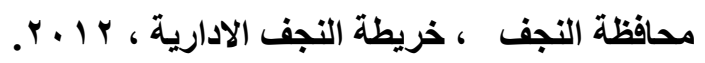

r _السطح :- يتكون سطح المحافظة من قسمين رئيسين هما السهل الرسوبي الذي يقع في الجزء الثمالي الثرقي من

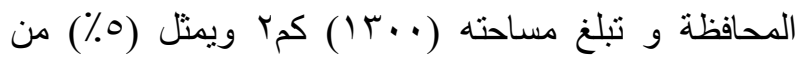

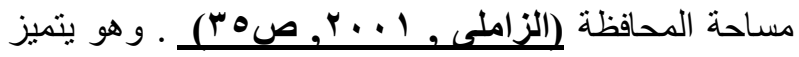
بأنبساطه و انحداره التدريجي من الثمال الى الجنوب ، اذ يمر خط الارتفاع (·r) م فوق سطح البحر في جهاته الثمالية ، 
جيدة من المو اد العضوية وقد ادى هذا الى استثمار ها بصورة الها كثيفة وقد ساعد على ذللك توفر جميع مقومات الانتاج

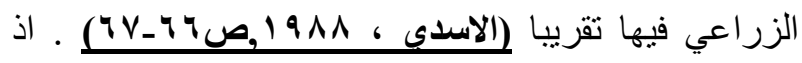
تسود القسم الثرقي من منطقة الدراسة التربة الغرينية المزيجية ضمن مناطق كتوف الانهار روهي تربة جيدة الصرف ذات نفاذية متوسطة(^V, · م/يوم)وقليلة|لملوحة

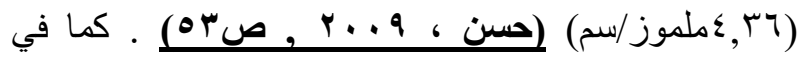
الخريطة ( ؟ ) , لذا فهي ملائمة لنمو المحاصيل الزر اعية اذ لـ

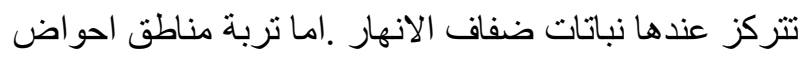
الانهار والتي تغطي معظم مساحة هذا القسم من المحافظة

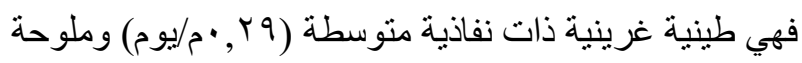

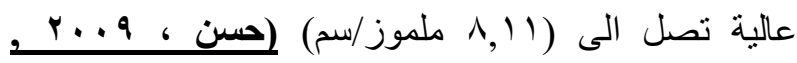
صه0), لذا يمكن استثمار ها قدر الامكان بالمحاصيل التي تتحمل الملوحة كمصصول الثعير ـ كما تظهر في الاقسام الثمالية الشرقية و الاقسام الجنوبية من المحافظة نربة الاهو ار و المستنقعات وهي تربة طينية غرينية ذات مستوى

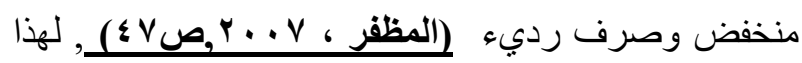
نجد ان زراعة المحصولين تتركز في الترب السهلية من وصن

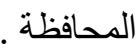
خريطة (ץ) انواع الترب في محافظة النجف

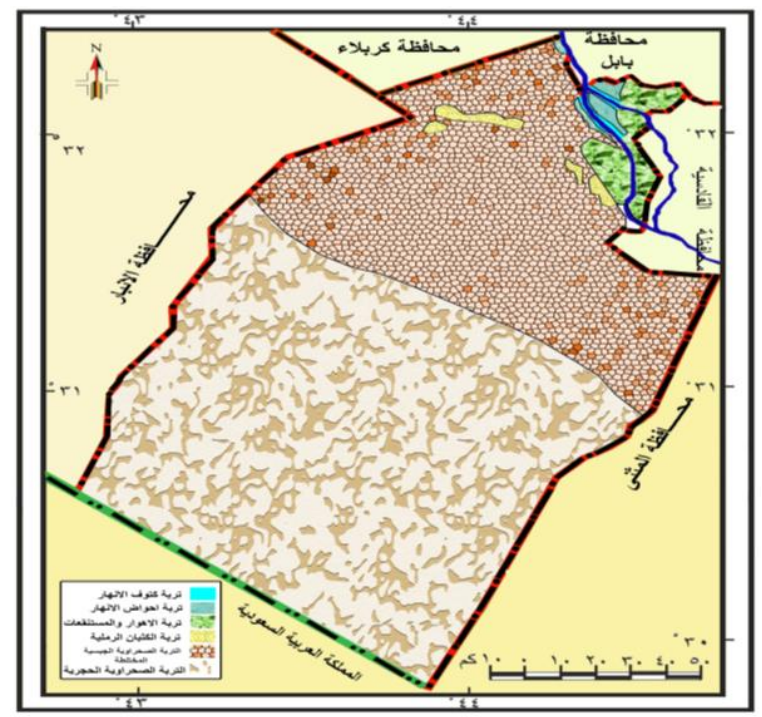

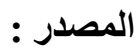

\section{P.Buringh, soils and soil conditions in Iraq} ,(wagenigen: H. veenman and Zonen N.V, 1960) Map,1.

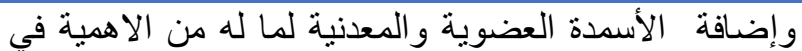
مساعدة البذور على الانبات السريع ويتجنب امر اض التربة وتكوين بادرات قوية وسليمة لتعطي بعد ذلك نموا خضريا جيدا وانتاجا وفيرا من المحصولين ـ كما يساعد السطح السهلي قليل الانحدار على استخدام طريقة الزراعة بالتسطير باستخدام البذارات التي تعتبر من الطر ائق الحديثة الموصى بها اذ تساعد على انتظام توزيع الحبوب وثبات عمق الزراعة والحصول على نباتات متجانسة وكذلك خلط البذور بالأسمدة والمبيدات الكيميائية وتتبع بعد ذلك عمليات الخدمة كالتزحيف والحش والتمشيط وكذللك الري و التسميد

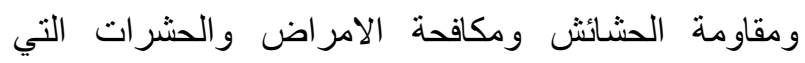

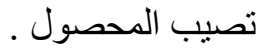

r-المناخ : يتصف مناخ منطقة الدراسة بانه مناخا جافا

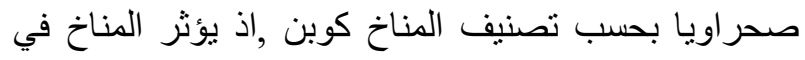
الانتاج الزراعي بشقيه النباتي والحيواني وهو العامل الذي يحدد نمو و انتاج المحاصيل الزراعية ونوعها ـ اذ ان لكل محصول زر اعي ظروف مناخية يستجيب لها وترتبط مر احل نموه بهذه الظروف في المنطقة ومع تباين مواقع تللك المحاصيل الزراعية الا انها متشابهة من حيث الاتتاج وطبيعته كما سيتم مناقثته في المبحث الثالث بالتفصيل. گ_التربة : تعد التربة عنصراً من عناصر البيئة الطبيعية التي تمثل اهمية لا يمكن تجاهلها في عمليات الإنتاج الزراعي , إذ أن أهميتها تكمن في كونها الوسط الذي يمد

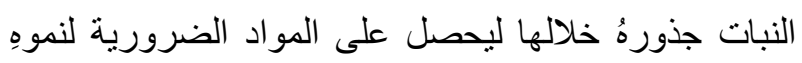
وتكاثره إذا ما توفرت الظروف الأخرى الملائمة لحركة

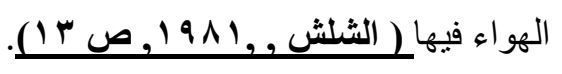
التربة في منطقة الدراسة تختلف في خصائصها الفيزيائية و الكيمياوية وبحسب العوامل التي ادت الى تكوينها

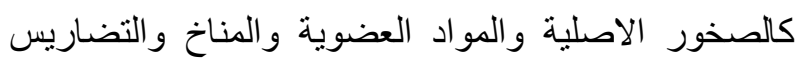

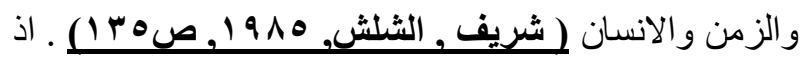
تعد تربة كتوف الانهار من اخصب ترب المحافظة بسبب قلة

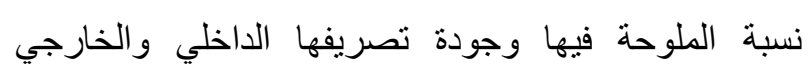
وملائمة خواصها الفيزيائية والكيميائية للإنتاج الزراعي ولهي

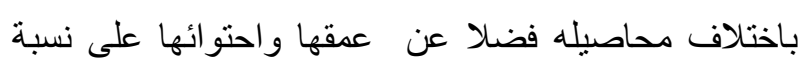




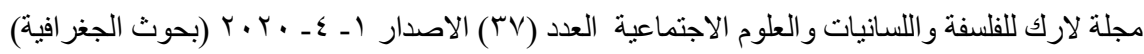

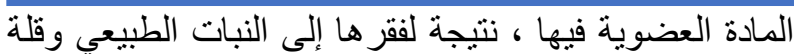
الرطوبة وارتفاع درجات الحرارة ، وتمتاز بانخفاض ملوحتها مقارنة بترب السهل الرسوبي ، وترتفع الملوحة في بعض المنخفضات نتيجة لقلة مياه الأمطار فيها وتعرضها للتبخر وتمتاز بكونها ضحلة إلى متوسطة العمق بسبب قلة

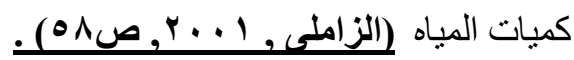
المبحث الثالث: أثر المناخ في زراعة محصولي القمح والثعير في محافظة النجف الاثرف

ان تحديد المناخ الزراعي الامثل والملائم للمحاصيل الزر اعية التي تتسجم متطلباتها المناخية مع طبيعة المعطيات المناخية المتوفرة ضمن منطقة الدراسة , لذا ينبغي التعرف على اهم العناصر المناخية ذات التأثير الفعال في عملية زر اعة القمح و الشعير و التي تتمثل بالاتي : -
بينما تغطي معظم القسم الغربي من المحافظة (منطقة الهضبة الصحراوية ) التربة الصحراوية ونربة الكثبان الرملية ، اذ تتميز بنسجتها الخشنة وفقر ها بالمواد العضوية وانخفاض منسوب المياه الجوفية فيها كما انها تكون رقيقة جدا بسبب تعرضها الى عوامل التجوية المختلفة وهي من الترب التي لا تصلح للإنتاج الزراعي الا على نطاق محدود وقد ساعد على ذلك عدم توفر مقومات الانتاج الزراعي الاخرى وخاصة موارد المياه الكافية لسد متطلبات الانتاج الزراعي ويعني ذلك انه بالإمكان زراعتها عند توفرتلك

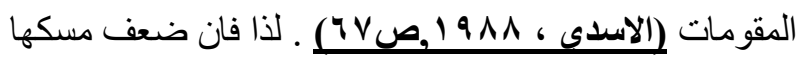
للماء ونفاذيتها العالية تسبب ضائعات مائية كبيرة عن طريق الرشح و الغمر بالعمق , لذا فهي تربة عطشى دائما وفقيرة و غير مستغلة زر اعيا الا على نطاق محدود جدا ـ يتضح لنا مما تقدم إن ترب الهضبة الغربية تمتاز بنسجتها الخشنة وقلة ا - الشعاع الشمسي : - يعد محصولي القمح والشعير من المحاصيل التي تحتاج الى نهار طويل نسبيا وتتمو نمو ا جيدا حينما تزيد الفترة الضوئية عن الحد الادنى الحرج ويز هران هذان المحصولان حينما يكون النهار طويلا وفترة الظلام قصيرة وذلك لان هذه

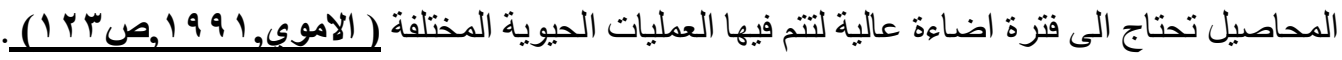
اذ ان القمح والشعير من المحاصيل الحقلية ذات النهار الطويل التي تحتاج الى فترة ضوئية لا تقل عن (ع ()ساعة ضوئية في

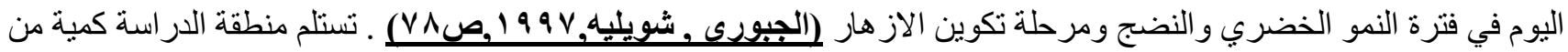

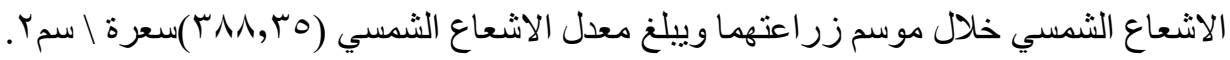
نلاحظ من الجدول (r) ان معدل كمية الاشعاع الشمسي في موسم زراعة المحصولين ابتداءا من شهر تشرين الثاني وكانون الاول

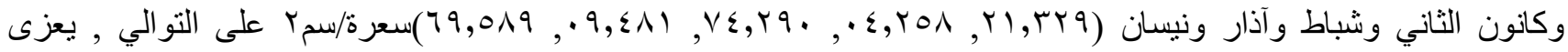
انخفاض معدل كمية الاشعاع الشمسي في موسم زر اعة المحصولين الى صغر معدل زاوية سقوط الاشعاع الشمسي وزيادة نسبة تغيم

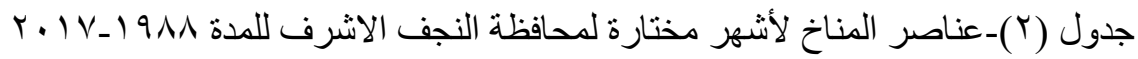

\begin{tabular}{|c|c|c|c|c|c|c|c|}
\hline المعددل & كانون & تثرين & نيسان & اذذار & شباط & كانون & \\
\hline $\begin{array}{r}\mu \wedge \Lambda, \mu \\
0\end{array}$ & $\begin{array}{r}Y \bullet \Lambda, \\
\varepsilon\end{array}$ & rqq, r & $\begin{array}{r}019,7 \\
9\end{array}$ & $\begin{array}{r}\varepsilon \wedge 1, \\
q\end{array}$ & $r \wedge 1, r v$ & $r q,, v \leq$ & كمية/الإشعاع الثمسي \\
\hline $1 \cdot, 9$ & $9.9 V$ & $1 \cdot, Y \wedge$ & $I r, \cdot V$ & $11, r$ & 11,49 & $1 \cdot, \leqslant 9$ & ساعات $\quad$ النظريـة /يوم \\
\hline
\end{tabular}




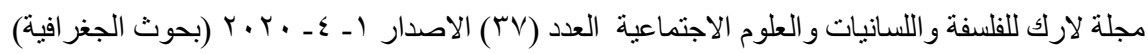

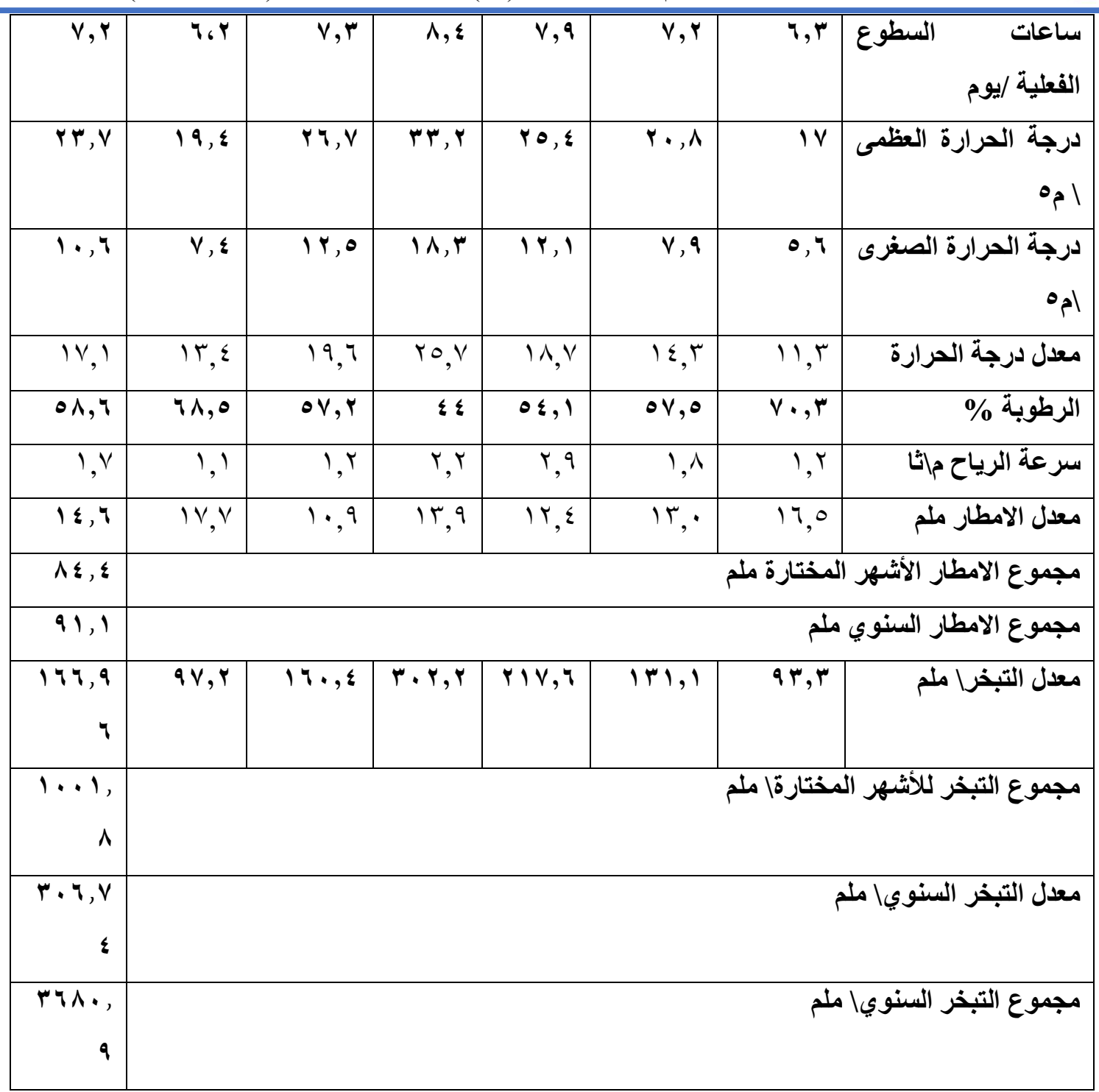

المصدر: وزارة النقل، الهيأة العامة للأنواء الجوية والرصد الزلزالي في العراق، قسم المناخ، بيانات غير منشورة ، I ـ ب . .

الاشعاع الشمسي كافية لنجاح زراعة محصولي القمح

و الثعبر .

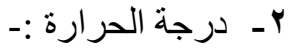

تعد درجة الحرارة من اهم عناصر المناخ التي تؤثر في نمو

وانتاج المحصولين , اذ ان لدرجات الحرارة دور واسع

وكبير في القيام بمعظم العمليات الحيوية كالامتصاص والتمثيل الغذائي , اذ تتطلب النباتات درجات حرارة متفاوتة حسب اطوار حياتها فلكل نبات ثلاث درجات حرارة ملائمة

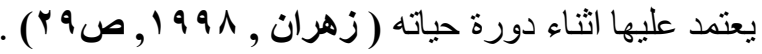
يتضح من جدول ( r ) ان درجة الحرارة الدنيا لنجاح زراعة محصول القمح هي (عمº) وان انخفاضها الى (-عُم) وبصورة مفاجئة خاصة ليلا الى قتل القمم النامية للنبات لتجمد الماء الموجود في السايتوبلازم وبين المسافات البينية
كما بلغت ساعات السطوع الفعلية في موسم زراعة المحصولين ابتداء من شهر تشرين الثاني وكانون الاول

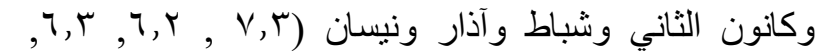

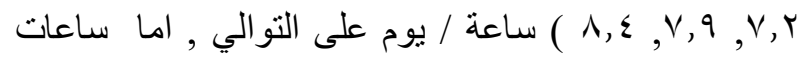
السطوع النظرية بلغت في موسم زراعة المحصولين ابتداء من شهر تشرين الثاني وكانون الاول وكانون الثاني وشباط

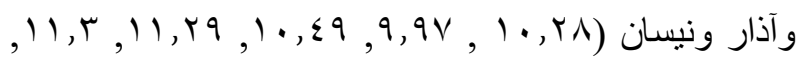
) ساعة / بوم على التوالي . ونرى ان ساعات السطوع الفعلية اقل من ساعات السطوع النظرية لأنها تتأتر بعو امل عديدة منها نسبة تغيم السماء وكذللك كثافة الاتربة و الغبار الموجود في الجو ـ و من هنا نجد ان الفارق بسيط بين المتطلبات الضوئية وكمية الاشعاع الشمسي , الا ان كمية 


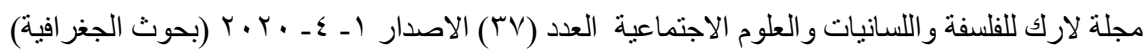

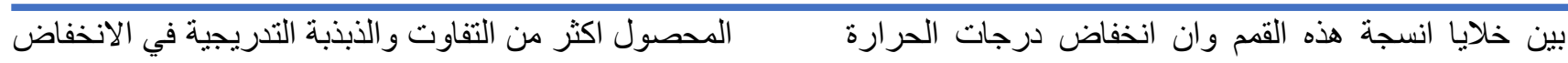

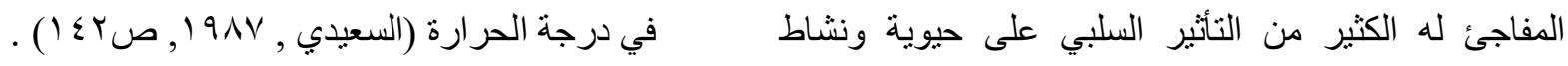
جدول (r)-المتطلبات الحرارية اللازمة لمحاصيل القمح والثعير

\begin{tabular}{|c|c|c|c|c|c|}
\hline درجة العليا الضسارة & دالدجة الدرارة & درجة الحرارة & درجة & درجة & اسم المحصول \\
\hline Th & $\varepsilon-$ & . r r & ro & $\xi$ & القمح \\
\hline$\varepsilon r$ & r & r. & ro & 1. & الشُعبر \\
\hline
\end{tabular}

المصدر: _محمد عبدالسعيدي، اساسيات انتاج المحاصيل الحقلية، بغداد , دار الحرية للطباعة,

المنتجة تحت ظروف جافة ومرتفعة الحرارة لاسيما خلال مدة التزهير وبعدها تكون صغيرة الحجم مما يجعلها غير صالحة للاستعمال الصناعي ويفضل استعمالها كعلف

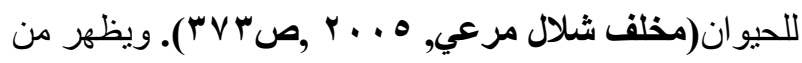
الجدول (Y) (Y) معدل درجة الحرارة لموسم زراعة

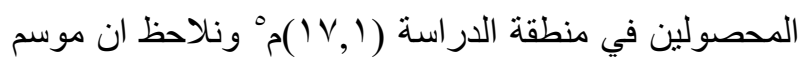
زراعة المحصولين تبدا من تشرين الثاني وكانون الاول وكانون الثاني وشباط واذار ونيسان اذ سجلت اعلى درجة

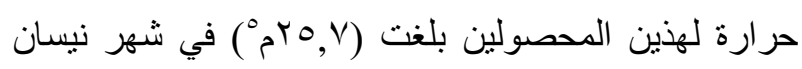
وادنى درجة لهما هي في شهر كانون الثاني اذ بلغت

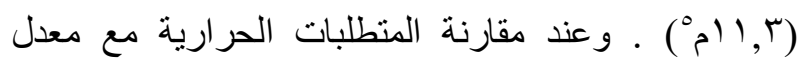
درجات الحرارة لمنطقة الدراسة نجد انها ملائمة لزراعة

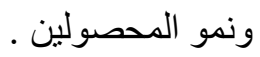

بـالامطار: تقع منطقة الدراسة ضمن المناخ الصحراوي الجاف اذ يرجع الى نمط مناخ (BWHS) بموجب تصنيف

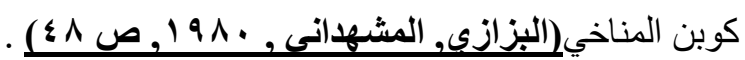
للأمطارتأثير على نمو وكثافة الغطاء النباتي وبمقتضى القانون الطبيعي فان تأثنير أي عامل يكون أكبر ما يمكن عندما تكون قيمته قريبة من الحد الادنى. ولما كانت الامطار قليلة ونادرة فان ازديادها عن المعدل المعتاد في سنة من السنين يكون لله بالغ الاثر على ازدهار الحالة النباتية. ولهذا

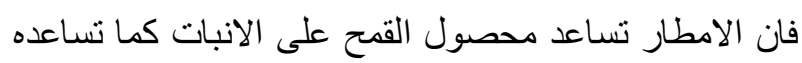
في امتصاص المغذيات والتمثيل الضوئي ولكن الامطار الغزيرة تعيق الزراعة في بداية الموسم وتسبب غسل النترات وزيادة احتمال الاصابة بالأمر اض وتعيق عملية التلقيح خلال
وان انخفاض درجة الحرارة الدنيا دون الحد الادنى لنمو هذا

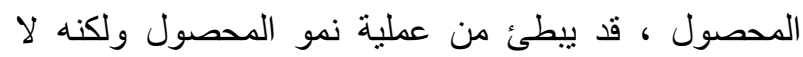
يؤدي الى توقف عملية النمو نهائيا خاصة وان محصول لهول لهول القمح له القدرة على تحمل درجات حرارية تصل دون الصفر

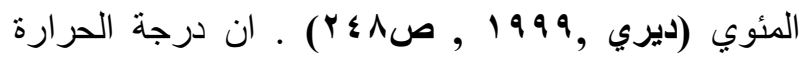
المثلى لزراعة هذا المحصول ونموه بشكل جيد فهي بحدود

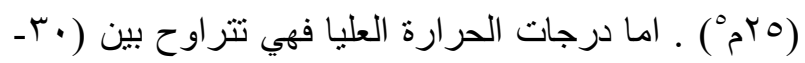

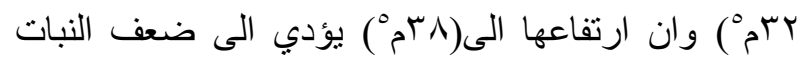
ونقص عدد السنابل ومن ثم نقص الحاصل وكما ان ارتفاع

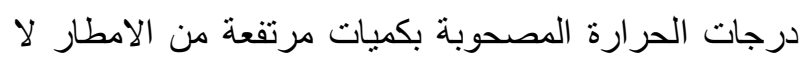
تناسب محصول القمح لان مثل هذه الظروف المناخية غالبا ما تساعد على انتشار الامراض الفطرية و البكتيرية

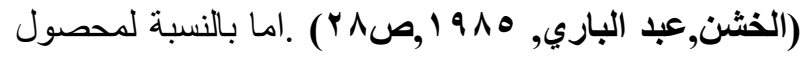
الشعير فان درجة الحرارة الدنيا لهذا المحصول تصل الى

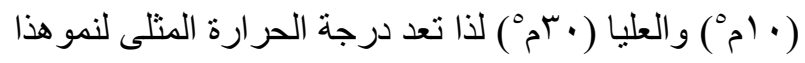

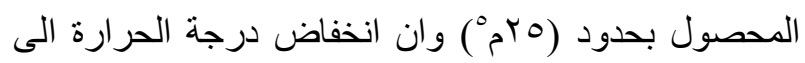
(r) ) يؤثر في انبات بذور الشعبر اذ يكون الانبات بطيئا جدا

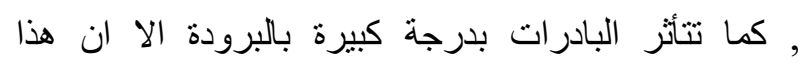
المحصول يحتاج الى درجات حرارة منخفضة في احد اطوار حياته وهي مدة النمو الخضري فيتهيأ المحصول للأز هار كما ديا ان الاصناف الثنوية المقاومة للبرودة من الشعير هي اكثر حساسية للبرودة من اصناف القمح الثنتية لذا فان زراعة

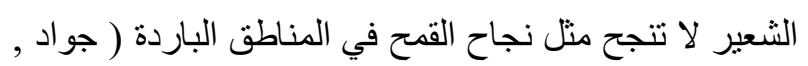

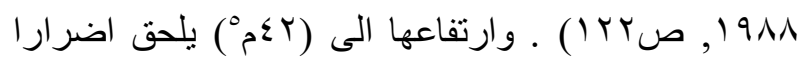
بمحصول الشعير وعلى الرغم من كون الشعير اكثر تحملا لارتفاع درجة الحرارة من القمح الا ان حبوب الثعير لثرير 


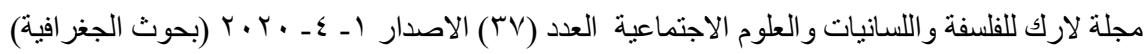

كما ينمو محصول الشعير في مناطق بيئية مختلفة وتسود

زر اعته في مناطق محدودة الامطار او ينمو بحدود مطرية تتراوح بين ( . . - . . . r )ملم لأنه يتحمل العطش و لايتحمل كثرة الرطوبة فالأخيرة تضر به و لاسيما في المر احل الاولى من نموه ومع ذلك فانه افضل محاصيل الحبوب مقاومة للجفاف الا انه يكون حساسا عند فقد الرطوبة في دور التفريع اذ ينتج عن ذلك قلة انتاج المحصول ( الشطاوي

$$
\text { . ( . . 9, }
$$

فترة التزهير فتتتج حبوب فارغة اماعند مرحلة النضج الحليبي فقد تسبب انحناء المحصول واضطجاعه

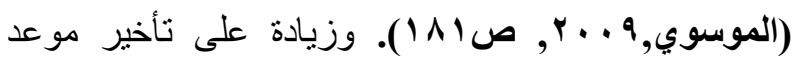
الحصاد عن موعده مما يسبب تلف في المحصول وخسارة في الانتاج , وعلى الرغم من ذلك فان سقوط الامطار يقلل من عدد الريات المقدمة , فان محصول القمح يحتاج الى

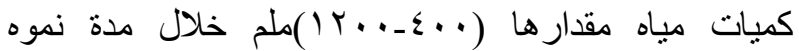

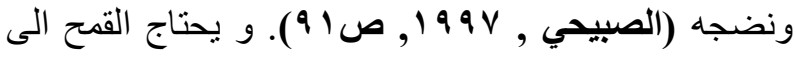

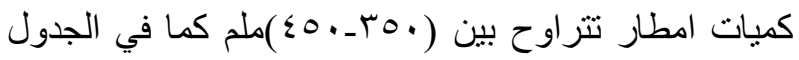

رقم (乏)

جدول (ع)-منطلبات محصولي القمح والشعيرمن بعض عناصر المناخ (الامطار _الرياح ـالرطوبةالنسبية)

\begin{tabular}{|c|c|c|c|}
\hline الرطوبة النسبية (\%) & الرياح (كم|ساعة ) & الامطار (ملم) & اسم المحصول \\
\hline$V$. & $v-7,0$ & $\leqslant 0,-\mu_{0}$. & القمح \\
\hline$V$. & $V-7,0$ & $r \ldots . r .$. & الشعير \\
\hline
\end{tabular}

المصدر :- عبد الحميد احمد يونس واخرون , محاصيل الحبوب , وزارة التعليم العالي والبحث العلمي , جامعة الموصل , دار

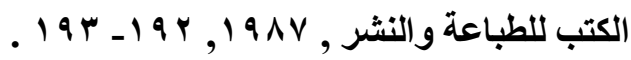

(الرطوبة المطلقة ) في درجة حرارة معينة وبين ما يمكن لذلك الهواء ان يستوعبه من بخار الماء في درجة الحرارة نفسها (القدرة ) و عندما يكون الهواء قد وصل الى حالة الاشباع فان رطوبته النسبية تكون قد وصلت الى . . 1

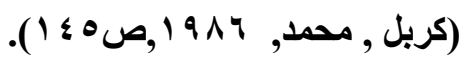
تعد الرطوبة النسبية من عناصر المناخ المؤثرة بالمحاصبل الزر اعية , من خلال علاقتها العكسية بعمليتي التبخر والنتح , إذ يؤدي انخفاضها الى تنشيط هاتين العمليتين والى زيادة الاحتياجات المائية للنبات , فضلا عما تسببه من ضياع مائي وتملح للتربة (السميع , ع . . Y, ص ع ب I). تتأثر الرطوبة النسبية بعدة عو امل مناخية اهمها درجة الحرارة , لذا فان الرطوبة النسبية تختلف خلال اليوم والشهر والسنة كما وتزداد في فصل زراعة المحصولين , نجد ان الرطوبة النسبية ترتبط بعلاقة عكسية مع درجات الحرارة , اذ بلغت الرطوبة النسبية اعلى معدلات لها في فصل الثتاء , اذ اذ سجلت في اشهر كانون الاول وكانون الثاني وشباط (11,0

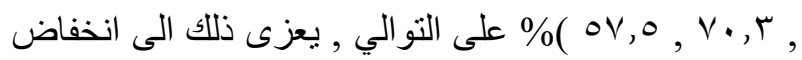
درجات الحرارة وسقوط الامطار وتعرض منطقة الدراسة الى كتل هو ائية باردة رطبة في هذا الفصل ـ كما ترتبط القيمة
تتميز الامطار الساقطة على منطقة الدر اسة بانها فصلية قليلة ومتذبذبة لايزيد مجموعها السنوي عن (ع,19)ملم , اذ انها تبدا بالسقوط اعتبار ا من شهر تشرين الاول (†, (Y)ملم تاخذ بعدها بالازدياد لتصل الى أعلى حد لها في شهر كانون الاول ملم و ثم تأخذ بالانخفاض التدريجي الى ان تنقطع (IV,V) نهائيا خلال اشهر الصيف جدول (Y) . لذا عند مطابقة الاحتياجات المائية لمحصول القمح من كميات الامطار الساقطة في منطقة الدراسة يتضح ان منطقة الدراسة واقعة خارج نطاق الخط المطري المسموح به للزر اعة الديمية وهو

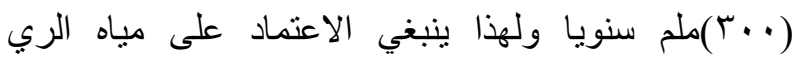
السطحية والجوفية لسد احتياجات المحصول المائية ـ وكما يتميز محصول الشعير بانه اقل محاصيل الحبوب احتياجا للمتطلبات المائية . عـالرطوبة : تعني الرطوبة بخار الماء الموجود في الهواء , واستعملت اساليب متعددة للتعبير عن حالة الرطوبة الهواء

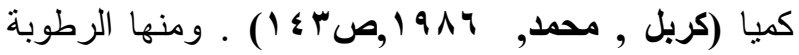
النسبية التي تعد من اكثر المصطلحات المتعلقة بالرطوبة اهمية وشيوعا في موضوعات الطقس والمناخ ونعني بها النسبة المئوية بين كمية بخار الماء الموجود فعلا في الهواء 


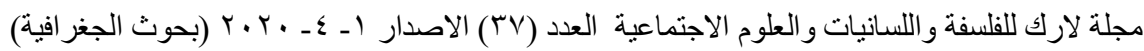

وبالتالي هذا يشجع على زراعة الأب المحصولين في منطقة الدراسة .

الرياح : يتباين تاثير الرياح بحسب سر عتها ومقدار ما تحمله من رطوبة وبخار ماء واتربة ولها ناثير سلبي وايجابي

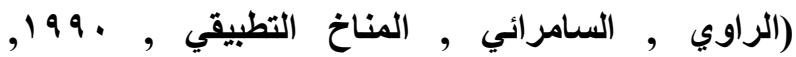
صس و 1). فالرياح الخفيفة مثلا تنشط من فعاليات النبات الحيوية في عملية صنع الغذاء وتساعد على تجديد عناصر الهو اء المحيطة به ـ وتعمل على خفض نسبة رطوبة التربة ودرجات الحرارة في المناطق الحارة وتعمل ايضا على نقل حبوب اللقاح من نبات الى اخر او ازهار النبات الواحد , وتستفيد معظم النباتات ومنها محصولي القمح والثعير من الرياح في عملية التلقيح الذاتي (سعد , ع . . Y ص ص V). وتسبب الرياح الثديدة مشكلة الاضطجاع لمحصولي القمح والشعير وهذه الظاهرة مشكلة في المناطق الاروائية بصورة خاصة عندما يكون الري السطحي كثيرا والتربة خفيفة والمحصول ضعيف السيقان وتظهر هذه المشكلة في

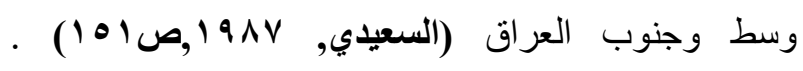
ونلاحظ من الجدول (r) ان معدل سرع هذه الرياح خلال موسم زراعتهما يصل الى (Y, (ماثا ) وهي سرع قليلة مقارنة مع مطلبات المحصولين و التي تتراوح ما بين (0, 7 Vكم| ساعة ) . الا ان زيادة سرع الرياح نهارا وبخاصة الفترة الاخيرة من نضج المحصولين التي تؤدي الى اضطجاع النباتات وتعرض السنابل للآفات الارضية فضلا عن صعوبة الحصاد الالي مما يتطلب استخدام الحصاد البدوي مما يزيد من تكاليف الانتاج وما يرافق ذلك من

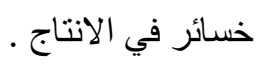

المبحث الرابع: اثر الموارد المائية في زراعة محصولي القمح والشعير في محافظة النجف الاثرف

يعد الماء اساس الحياة لكل الكائنات الحية , وان كميته في التربة تحدد كثافة وحجم النبات,وترتبط الاراضي الزر اعية بكمية المياه المتاحة ونوعها وهي على نو عين تعتمد جميعها على الهطولات المطرية كمصدر رئيس لتغذية المياه

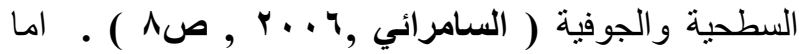
المياه السطحية وهي المصدر الرئيسي للموارد المائية في القسم الثرقي من المحافظة (منطقة السهل الرسوبي ) فتتمثل
الفعلية للأمطار بالرطوبة النسبية ومقدار ما بضيع منها عن طريق التبخر اذ لايزيد معدل الرطوبة النسبية خلال موسم زر اعتها في محافظة النجف الاشرف على (†, ؟^\%) لذا فان محصول القمح لايناسبه الجو المصحوب بالرطوبة العالية في مر احل نموه الاولى اذ تؤدي الى انتاج حبوب غير جيدة لان مثل هذه الظروف تشجع على انتشار امراض الصدأ بصورة وبائية وافضل رطوبة لمحصول القمح هي التي تبلغ (• • ) ( يونس , r99 19, ص \& \& 1). كما ان قلة الرطوبة النسبية تعني زيادة قيمة الضائعات المائية والحاجة الى موارد مائية اضافية وفي حال عدم توفرها ستؤثر سلبا في انتاجية المحصول. ويتميز محصول الثعير بانه من اكثر المحاصيل الشتوية تحمل لنقص الرطوبة النسبية وان الزيادة في الرطوبة بعد التزهير تعيق عملية النضج الطبيعي , اذ يتم انتاج حبوب خفيفة الوزن وتكون نسبة النتروجين المستخلص فيها عالية ـ اما اذا انخفضت الرطوبة النسبية فانها تؤدي الى انتاج حبوب لا تصلح الا للعلف الحيواني كما في المناطق الجافة وشبه الجافة لذا فان انتاج محصول الشعير الجيد

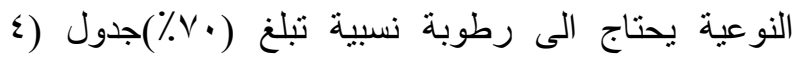
)لاتمام كافة العمليات التي يحتاجها في مراحل نموه المختلفة(حسين ,عبد الحسين, (99 | ,ص 99 | |) . التبخر : لا يقتصر تاثير التبخر على فقد الماء من النبات عن طريق النتح فحسب لكنه يعمل ايضا على انقاص المحتوى المائي للتربة ـ كما ان تباين التبخر من فصل لآخر هي سمة منطقة الدراسة سنويا كما وتزداد عملية التبخر في المناطق الجافة طبقا لتاثير العوامل الجوية , فترتفع كمية التبخر مع ارتفاع درجات الحرارة وتعرف هذة العملية بالنتح عند

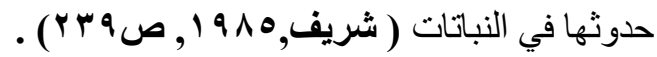
وييلغ معدل التبخر خلال موسم زراعتهما (79,97 (17)

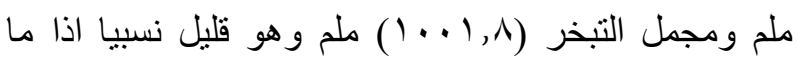

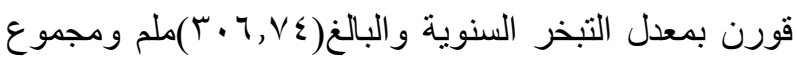
التبخر السنوي (9, • ^^ץ) ملم كما في جدول (Y ) . ويعزى سبب ذلك الى ارتفاع الرطوبة النسبية وسقوط الامطار و انخفاض درجة الحرارة وكثرة الغيوم ـ لذا اثر ذلك في قلة استهلاك محصول القمح والشعير من المياه خلال فصل الشتاء وارتفاع الاستهلاك من المياه نهاية الموسم الشتوي . 


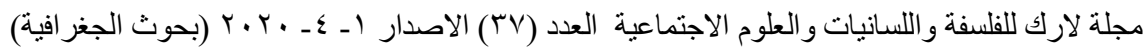

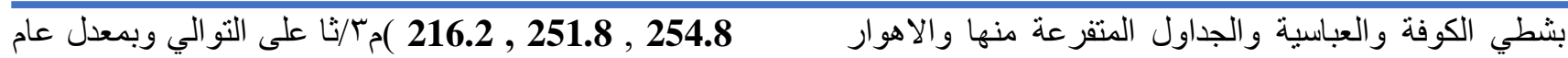

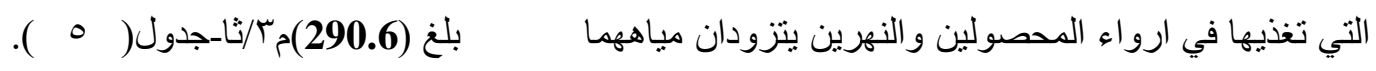

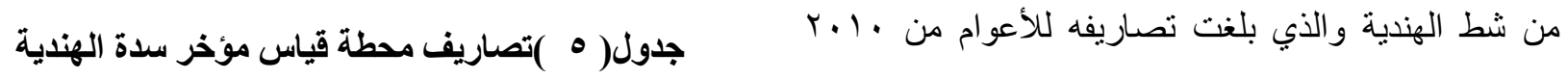

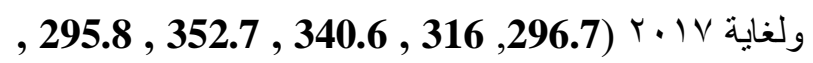

\begin{tabular}{|c|c|c|c|c|c|c|c|c|c|c|c|c|c|}
\hline السنوي & أيلول & آب & تموز & حزيران & مايس & نيسان & آذار & شباط & Fك & ك & ت & ت & المائية \\
\hline 296.7 & 279 & 317 & 367 & 313 & 264 & 272 & 286 & 307 & $\mathbf{1 5 0}$ & 248 & 317 & 340 & 2010 \\
\hline 316 & 295 & 335 & 388 & 330 & 279 & 287 & 302 & 324 & 158 & 300 & 335 & 359 & 2011 \\
\hline 340.6 & 319 & 362 & 419 & 356 & 301 & 310 & 326 & 350 & 170 & 324 & 362 & 388 & 2012 \\
\hline 352.7 & 328 & 366 & 401 & 367 & 321 & 312 & 335 & 379 & 201 & 355 & 376 & 391 & 2013 \\
\hline 295.8 & 288 & 311 & 336 & 293 & 285 & 271 & 275 & 307 & 171 & 312 & 330 & 271 & 2014 \\
\hline 254.8 & 239 & 275 & 314 & 281 & 210 & 226 & 241 & 269 & 132 & 243 & 237 & 291 & 2015 \\
\hline 251.8 & 229 & 254 & 290 & 257 & 225 & 227 & 236 & 271 & 140 & 254 & 265 & 274 & 2016 \\
\hline 216.2 & 197 & 222 & 236 & 229 & 195 & 187 & 204 & 231 & 119 & 210 & 230 & 234 & 2017 \\
\hline 290.6 & 270.7 & 303.6 & 340.6 & 301.9 & 259.43 & 260 & 274.1 & 304.4 & 255.9 & 285.4 & 305 & 315.4 & مبراثا \\
\hline
\end{tabular}

المصدر: - جمهورية العراق , وزارة الموارد المائية , المركز الوطني لادارة الموارد المائية , بيانات غير منشورة , 11 • ؟.

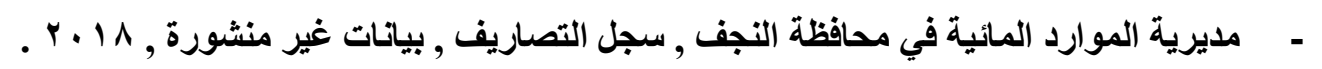

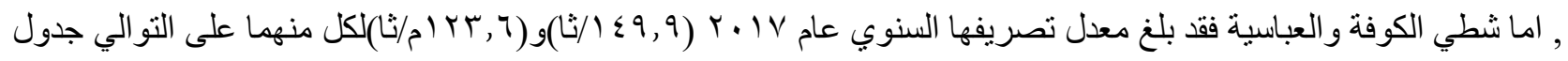

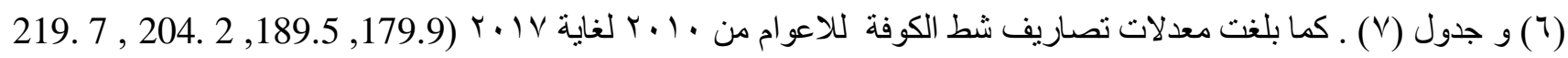

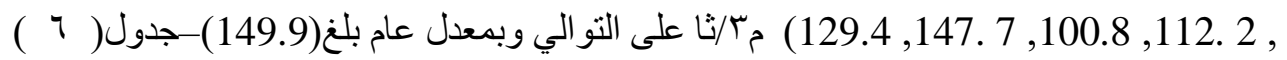

جدول( 7 ) ) تصاريف محطة قياس مؤخر سدة الكوفة

\begin{tabular}{|c|c|c|c|c|c|c|c|c|c|c|c|c|c|}
\hline السنوي & أيلول & آب & تموز & حزيرا & مايس & نيسان & آذار & شُباط & كو & كا & ت & ت & المائية \\
\hline 179.9 & 167 & 190 & 220 & 188 & 158 & 156 & 172 & 184 & 150 & 170 & 190 & 204 & 2010 \\
\hline 189.5 & 177 & 202 & 233 & 198 & 167 & 172 & 181 & 194 & 154 & 180 & 201 & 215 & 2011 \\
\hline 204.2 & 191 & 217 & 251 & 214 & 180 & 186 & 196 & 210 & 162 & 194 & 217 & 232 & 2012 \\
\hline
\end{tabular}




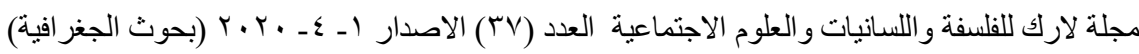

\begin{tabular}{|l|r|r|r|r|r|r|r|r|r|r|r|r|r|}
\hline 219.7 & 197 & 219 & 240 & 220 & 192 & 187 & 281 & 227 & 213 & 171 & 255 & 234 & 2013 \\
\hline 112.2 & 106 & 115 & 124 & 108 & 105 & 101 & 113 & 99 & 138 & 115 & 122 & 100 & 2014 \\
\hline 100.8 & 84 & 93 & 107 & 95 & 77 & 83 & 89 & 99 & 85 & 89 & 87 & 107 & 2015 \\
\hline 147.7 & 118 & 133 & 174 & 154 & 135 & 136 & 141 & 162 & 144 & 152 & 159 & 164 & 2016 \\
\hline 129.4 & 118 & 133 & 141 & 137 & 117 & 112 & 122 & 138 & 131 & 126 & 138 & 140 & 2017 \\
\hline 149.9 & 144.8 & 8 & 3 & 3 & 4 & 6 & 9 & 1 & 1 & 6 & 1 & 5 & \multicolumn{1}{|c|}{5} \\
& & 162. & 186. & 164. & 141. & 141. & 161. & 164. & 147. & 149. & 171. & 174. & 5 \\
\hline
\end{tabular}

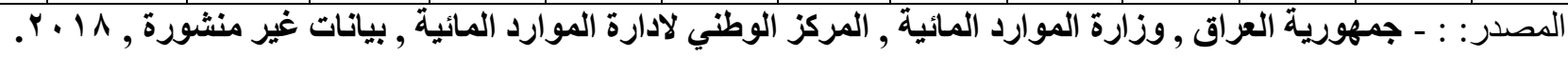

- مديرية الموارد المائية في محافظة النجف , سجل التصاريف , بيانات غير منشورة , 11 ـ ـ .

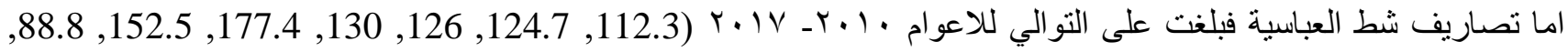

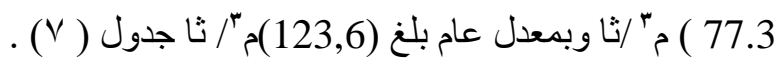

جدول (V) تصاريف محطة قياس مؤخر سدة العباسية

\begin{tabular}{|c|c|c|c|c|c|c|c|c|c|c|c|c|c|}
\hline السنوي & أيلو & آب & تموز & حزيران & مايس & نيسان & آذار & شباط & ك5 & ك5 & ت & تا & السنة المائية \\
\hline 112.3 & $\begin{array}{r}10 \\
6\end{array}$ & 120 & 139 & 118 & 100 & 103 & $\begin{array}{r}10 \\
8\end{array}$ & 116 & 95 & 94 & 120 & 129 & 2010 \\
\hline 124.7 & $\begin{array}{r}12 \\
1\end{array}$ & 137 & 159 & 135 & 114 & 109 & $\begin{array}{r}11 \\
4\end{array}$ & 123 & 98 & 117 & 127 & 136 & 2011 \\
\hline 126 & $\begin{array}{r}11 \\
8\end{array}$ & 135 & 148 & 135 & 118 & 114 & $\begin{array}{r}12 \\
0\end{array}$ & 129 & 99 & 119 & 134 & 143 & 2012 \\
\hline 130 & $\begin{array}{r}12 \\
1\end{array}$ & 135 & 148 & 135 & 118 & 115 & $\begin{array}{r}12 \\
3\end{array}$ & 140 & 111 & 131 & 139 & 144 & 2013 \\
\hline 177.4 & $\begin{array}{r}17 \\
2\end{array}$ & 187 & 201 & 176 & 171 & 163 & $\begin{array}{r}16 \\
5\end{array}$ & 184 & 163 & 187 & 198 & 162 & 2014 \\
\hline
\end{tabular}




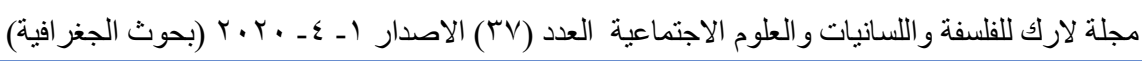

\begin{tabular}{|c|c|c|c|c|c|c|c|c|c|c|c|c|c|}
\hline 152.5 & $\begin{array}{r}14 \\
3\end{array}$ & 165 & 187 & 168 & 126 & 135 & $\begin{array}{r}14 \\
4\end{array}$ & 161 & 139 & 145 & 142 & 175 & 2015 \\
\hline 88.8 & 69 & 88 & 104 & 92 & 81 & 81 & 84 & 97 & 86 & 91 & 95 & 98 & 2016 \\
\hline 77.3 & 70 & 79 & 84 & 82 & 70 & 67 & 73 & 83 & 78 & 75 & 82 & 84 & 2017 \\
\hline 123.6 & $\begin{array}{r}11 \\
5\end{array}$ & 30.8 & $\begin{array}{r}146 . \\
3\end{array}$ & 130.1 & $\begin{array}{r}112 . \\
2\end{array}$ & $\begin{array}{r}110 . \\
9\end{array}$ & $\begin{array}{r}11 \\
6.4\end{array}$ & $\begin{array}{r}129 . \\
1\end{array}$ & $\begin{array}{r}108 . \\
6\end{array}$ & $\begin{array}{r}119 . \\
9\end{array}$ & $\begin{array}{r}129 . \\
6\end{array}$ & $\begin{array}{r}133 . \\
9\end{array}$ & المعدل \\
\hline
\end{tabular}

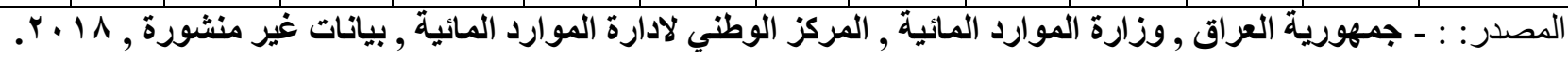

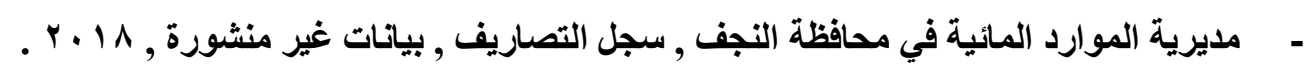

بالإضافة الى اثر بقية العوامل الجغرافية الأخرى بالاخص

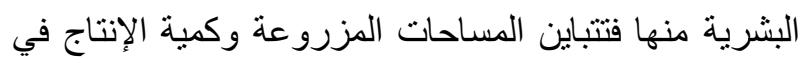

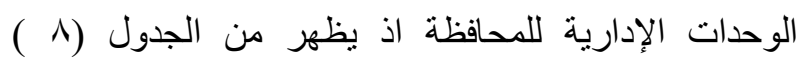

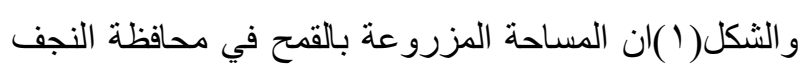

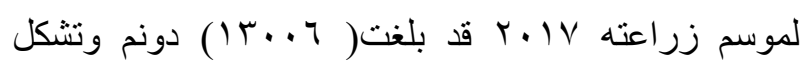
(1) (1) من اجمالي المساحة المزروعة بالقمح في العراق

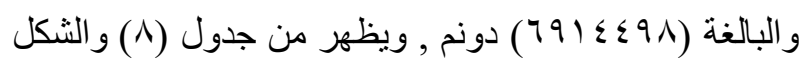

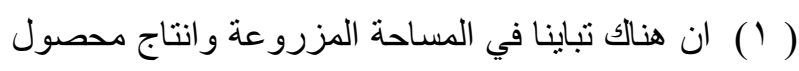

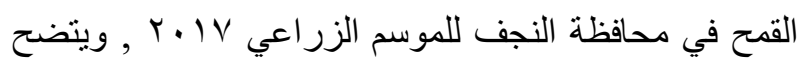
من الجدول و الخريطة المذكورين ان ناحية القادسية قد جاءت بالمركز الاول في المساحة المزروعة بهذا المحصول والتي

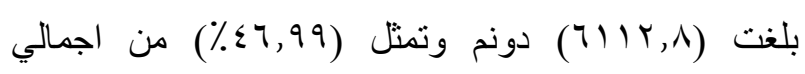
المساحة المزروعة بهذا المحصول في المحافظة تلتها في المركز الثاني ناحية العباسية بمساحة وصلت الى بـانى

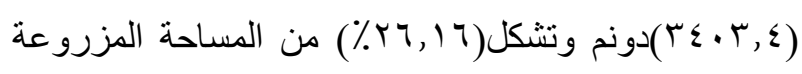
بالقمح في منطقة الدراسة وجاءت بالمركز الثالث مركزقضاء النجف وقد بلغت المساحة المزروعة بها بمحصول القمح

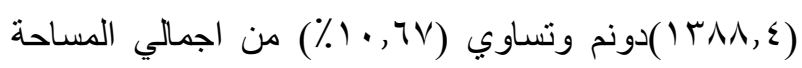
المزروعة بهذا المحصول في محافظة النجف ــ اما بقية الوحدات الادارية فقد تراوحت المساحة المزروعة بالقمح

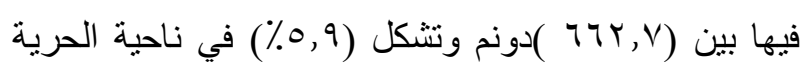
و) (VY, 20 دونم وتساوي (00, • •) في مركز قضاء المناذرة
ومن خلال ترجمة ارقام وقياسات مؤخرات سدات الهندية والكوفة والعباسية , نلاحظ ان هناك تذبذب في كميات المياه

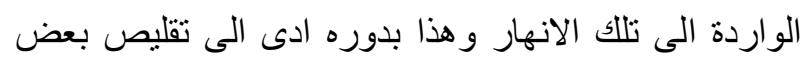

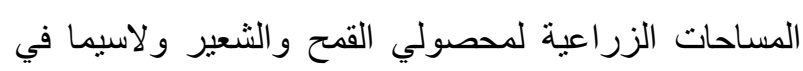

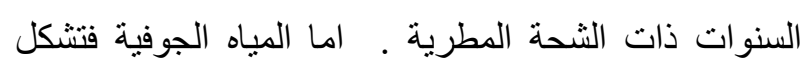
المصدر الرئيسي في القسم الغربي من المحافظة , وذلك لقلة الامطار الساقطة و عدم وجود مصدر للمياه السطحية , الا ان

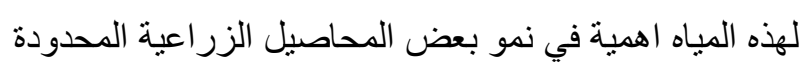

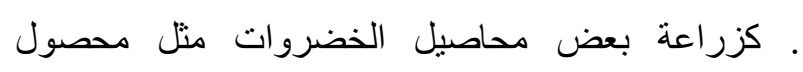
الطماطة والخيار و البصل و غير ها من المحاصيل الاخرى , برّل اما الأمطار فدورها محدود جدا كونها امطارا فصلية قليلة متذبذبة لكنها مع ذلك تساعد نسبيا على نمو المحصولين . تؤثز الموارد المائية في زراعة محصولي القمح والشعير في محافظة النجف الاشرف بشكل متباين فهي من المحدات الرئيسة لزراعة هذين المحصولين كون المنطقة تقع ضمن المناخ الجاف والذي يتطلب نوفير كميات كافية لزراعة ونمو المحصولين ونتباين في اعتمادها على المياه

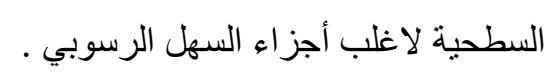

المبحث الخامس: التوزيع الجغرافي لانتاج محصولي القمح والثعير في محافظة النجف الاشرف: - لئن الجغرافي لانتاج

يوضح هذا المبحث التوزيع الجغرافي للمحصولين في منطقة الدر اسة في ضوء تأثر هما بعنصري المناخ و الموارد المائية 


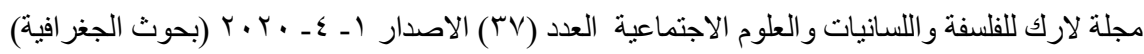

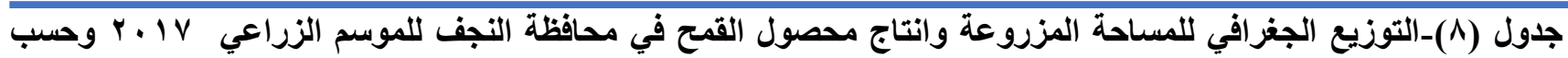

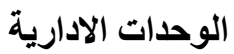

\begin{tabular}{|c|c|c|c|c|c|}
\hline & & & & & القمح \\
\hline 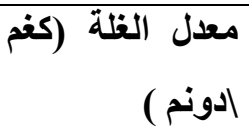 & $\begin{array}{r}\text { الامية النسبية } \\
\text { \% }\end{array}$ & الانتاج اطن & $\begin{array}{r}\text { الاهمية النسبية } \\
\text { \% }\end{array}$ & المساحة & : الادارية \\
\hline$\varepsilon \vee Y, \Lambda \varepsilon$ & 9,79 & $907 \leqslant \vee \leqslant, 9 \wedge \wedge$ & $1 \cdot, 7 \mathrm{~V}$ & $\mid r \wedge \Lambda, \varepsilon$ & النجف \\
\hline$\vee \vee \Lambda, 9 \varepsilon$ & $1, v$ & $1171 \varepsilon \cdot, \varepsilon \mu$ & 1,17 & $101, \cdot \varepsilon$ & \\
\hline $0.1,19$ & $11, \mu v$ & VVYY\0, \&Y0 & $11, \wedge r$ & lorq, \& & قضاء النجف \\
\hline YY०, \& & $\cdot, V V$ & OrOHY, & $\cdot, 7 \varepsilon$ & $\Lambda \varepsilon$ & مركز الكوفة \\
\hline $7 \leq 9, \leq 1$ & $r r, O r$ & $r Y \cdot r \mid r$ & $7 q, 17$ & $r \varepsilon, \mu, \varepsilon$ & \\
\hline フ $9, \wedge q$ & $7,1 \leq$ & $\leq 1 \vee \leqslant 11$ & 0,9 & צฯY,V & \\
\hline $7 \leqslant 0, \wedge 1$ & एq, $\varepsilon \varepsilon$ & $\nvdash \neg \Lambda \cdot 17 \cdot, \Lambda$ & $p_{1, q .}$ & $\{10,1$ & قضاء الكوفة \\
\hline rqv, Vr & $\cdot, \varepsilon Y$ & $r \wedge \wedge 10$ & $\cdot, 00$ & $V Y, \varepsilon 0$ & مركز المناذرة \\
\hline$q r r, q q$ & 4,99 & YVIVIO & $r, \mu \varepsilon$ & $\varepsilon \mu \Delta, 00$ & الحيرة \\
\hline $77 \cdot, 70$ & $7, \vee 7$ & $\varepsilon 09 \wedge 1 \%$ & $\bullet, \mu \bullet$ & 797 & المشخاب \\
\hline$\varepsilon r Y, Y V$ & $p V, q q$ & rOAIrr. & $\varepsilon 7,99$ & $711 Y, \Lambda$ & بـة \\
\hline$\{07, \vee 1$ & $\varepsilon 9,1 \wedge$ & rF\&। & $0 Y, Y 0$ & VHו I, A & قضاء المناذرة \\
\hline orr,rq & 99,99 & $q \vee q \leq r q q, r r$ & 99,91 & $1 \% \ldots$ & المحافظة \\
\hline
\end{tabular}

الري , و إمكانية إيصال ماء الري إلى ابعد نقطة في أراضيها

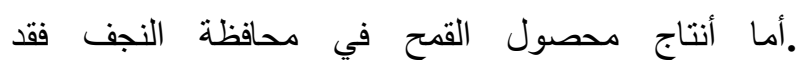
بلغ)

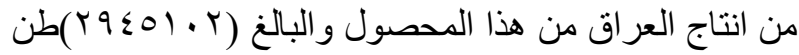
و ويتباين التوزيع الجغر افي لإنتاج القمح بين الوحدات الادارية.

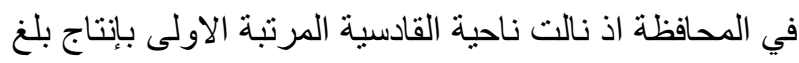

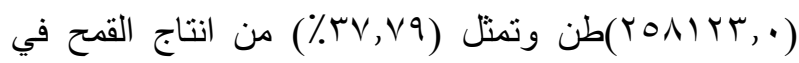
المحافظة (جدول ^) وشكل (r ) ) واحتلت ناحية العباسية

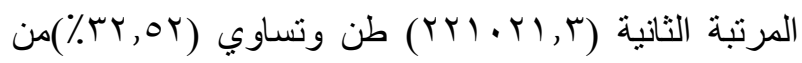
اجمالي انتاج القمح في المحافظة .اما المرتبة الثالثة فكانت من حصة مركز قضاء النجف وقد بلغ الانتاج فيها

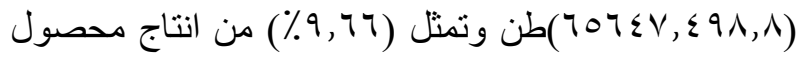
القمح في المحافظة ـ اما بقية الوحدات الادارية الاخرى فقد

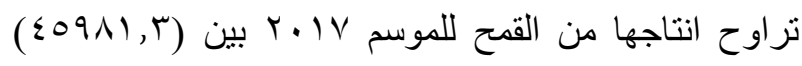

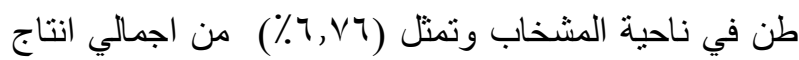

شكل (1)-المساحة المزروعة لمحصول القمح لمحافظة

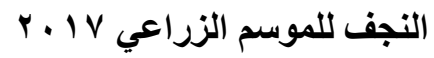

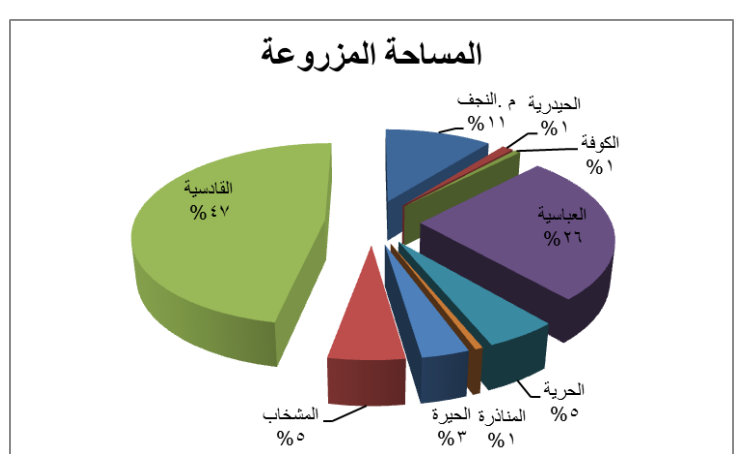

المصدر : من عمل الباحثين بالاعتماد على بيانات جدول

ويعزى سبب التباين في المساحة المزروعة بالقمح في

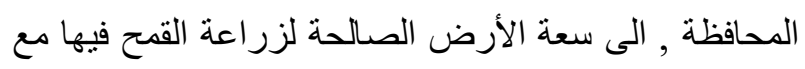
وفرة الموارد المائية المتمثلة بوجود عدد من الجداول وقنوات 


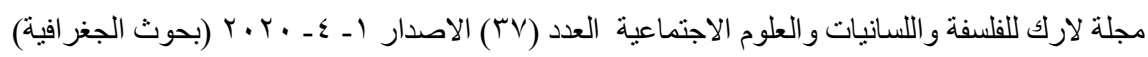

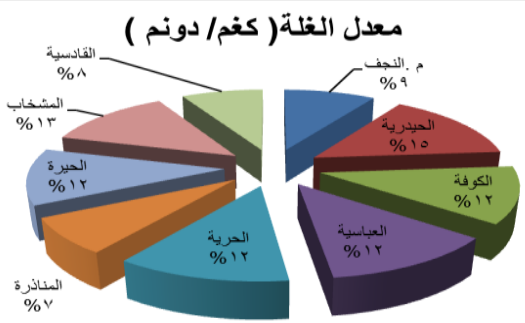

المصدر : من عمل الباحثين بالاعتماد على بيانات جدول

اما محصول الشعير فقد بلغت المساحة المزروعة به في

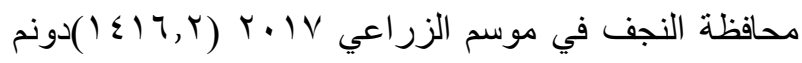

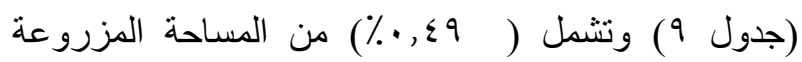

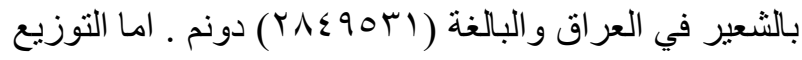
الجغر افي لهذا المحصول حسب الوحدات في محافظة فهناك تباين في ذلك فكان المركز الاول من نصيب مركز قضاء

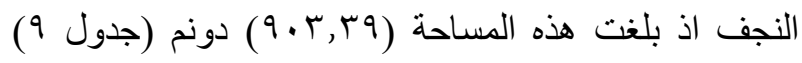

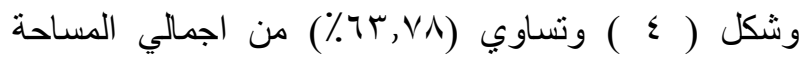
المزروعة في محافظة النجف, تلته ناحية الحيرة في المركز

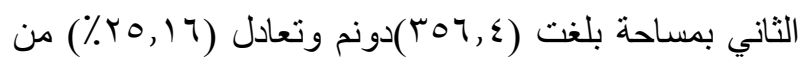
اجمالي المساحة المزروعة في منطقة الدراسة ـ اما المركز الثالث فكان من حصة ناحية الحيدرية بمساحة وصلت الى

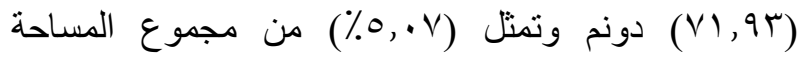
المزروعة في منطقة الدراسة ـ وتراوحت المساحة في بقية

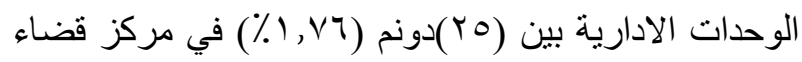

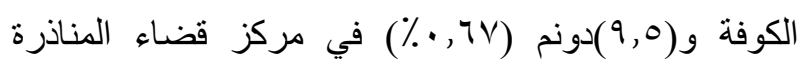
ويظهر من الجدول (9) ان هنالك اربعة وحدات ادارية وهي نواحي (العباسية ـ الحرية ـالمشخاب ـ القادسية ) لم تسجل

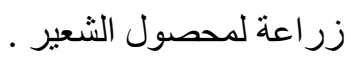

القمح و(YAN10)طن وتشكل (Y), •\%)في مركز قضاء

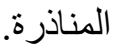

شكل (Y)-انتاجية محصول القمح لمحافظة النجف للموسم

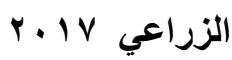

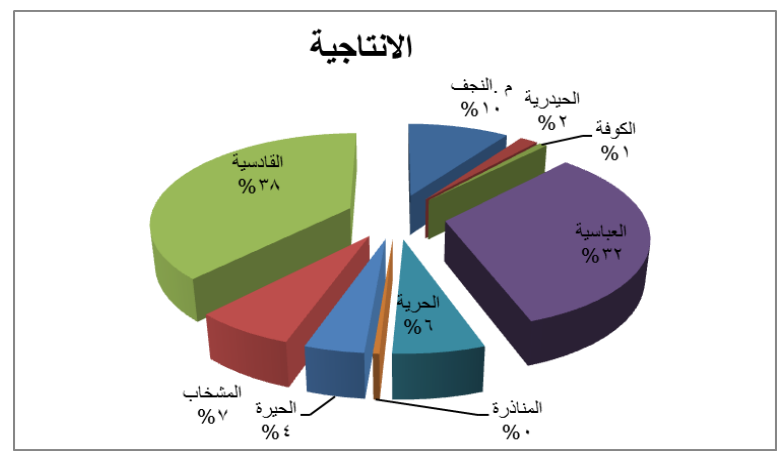

المصدر : من عمل الباحثين بالاعتماد على بيانات جدول

اما معدل غلة الدونم من القمح في محافظة النجف للموسم الزراعي فقد بلغت (q, r,

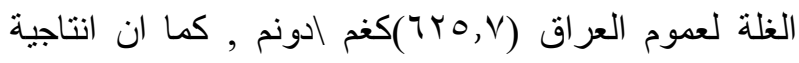
الدونم تختلف بين الوحدات الادارية اذ بلغ اعلاها

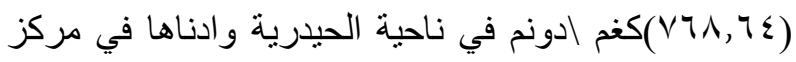

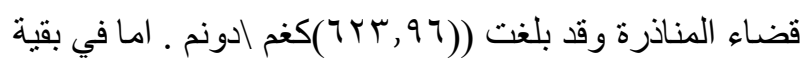
الوحدات الادارية فنتراوح بين غلة الدونم في الوحدتين

$$
\text { السابقتين الذكر (جدول ^) . }
$$

شكل (r)معدل الغلة (كفم ادونم ) محصول القمح لمحافظة r. IV r. النجف للموسم الزراعي

جدول (9)_التوزيع الجغرافي للمساحة|لمزروعة وانتاج محصول الثعيرفي محافظة/لنجف للموسم الزراعي IV إ. وحسب الوحدات الادارية

\begin{tabular}{|c|c|c|c|c|c|}
\hline & & & & & الشعير \\
\hline معدل الغلة (كفم & 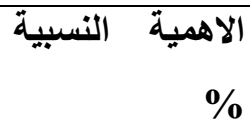 & الانتاج اطن & 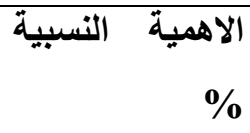 & المزروعة الدونم & الوحدة الادارية \\
\hline$\varepsilon \cdot \varepsilon, Y \Psi$ & $70, Y$. & rTOY. r & $\pi r, v \wedge$ & $q \cdot r, r q$ & مركز النجف \\
\hline
\end{tabular}




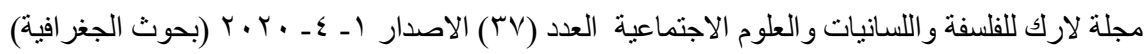

\begin{tabular}{|c|c|c|c|c|c|}
\hline 419,91 & $\varepsilon, 1$. & Yr. II & $0, v$ & VI, qu & الحيدرية \\
\hline 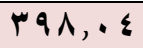 & 79,7 & 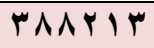 & $7 \wedge, \wedge\rceil$ & $q \vee v, r Y$ & قضاء النجف \\
\hline rqu,q & $1, \vee 0$ & $9 \wedge Y_{0}$ & $1, \vee 7$ & ro & مركز الكوفة \\
\hline - & . & . & - & - & الل - - - - الل \\
\hline - & - & . & . & . & الحرية \\
\hline$r q r, \varepsilon$ & $1, \vee 0$ & qAY० & $1, \sqrt{7}$ & ro & قضاء الكوفة \\
\hline$r \wedge 1, \vee q$ & $\cdot, \leqslant V$ & YqVV & $\cdot, 7 V$ & 9,0 & مركز المناذرة \\
\hline pq, & $r \varepsilon, q r$ & 1\%970. & $r 0,17$ & ए० & الحيرة \\
\hline . & - & - & . & - & المشخاب \\
\hline . & - & - & . & . & القادسية \\
\hline$r \wedge q, 01$ & $r 0, \varepsilon$. & $17199 V$ & $r \bullet, \wedge r$ & $\{10,9$ & قضاء المناذرة \\
\hline pqu, $\{0$ & $97, \leqslant 0$ & $07 \ldots \leq 7$ & $97, \leqslant 0$ & $1 \varepsilon 17, Y$ & المحافظة \\
\hline
\end{tabular}

المصدر : مديرية زراعة النجف , قسم الاحصاء , بيانات غير منشورة ، IV ب.

الشعير في منطقة الدراسة في الموسم الزر اعي V V ب تلته

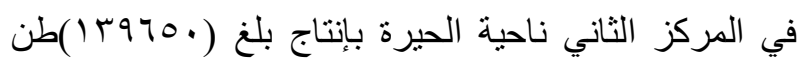

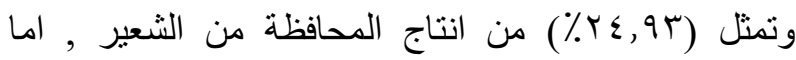
المركز الثالث فكان من حصة ناحية الحيدرية (1 (1 . ب)طن

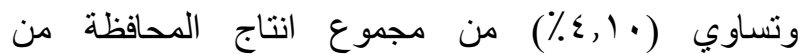
المحصول المذكور ولنفس الموسم ـ اما الانتاج في بقية

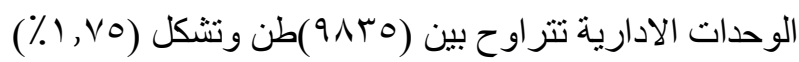

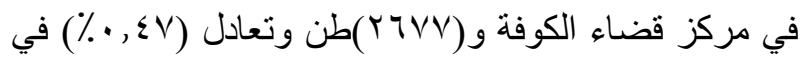
مركز قضاء المناذرة .

شكل (0)-انتاجية محصول الشعير لمحافظة النجف للموسم

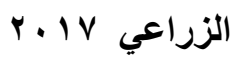

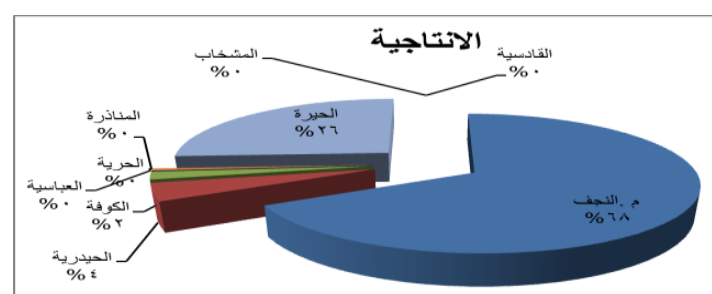

المصدر : من عمل الباحثين بالاعتماد على بيانات جدول

اما انتاجية الدونم من محصول الثعير في محافظة النجف

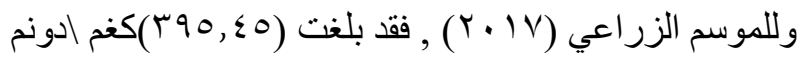

وفيما يتعلق بانتاج محصول الثعير في منطقة الدراسة

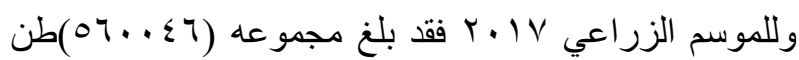
(جدول 9)وتمثل (0ء ,؟9\%) من اجمالي انتاج العراق البالغ

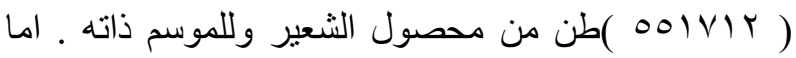
التوزيع الجغر افي لانتاج محصول الشعير في محافظة النجف وحسب الوحدات الادارية التي زرعت المحصول في الموسم الزراعي فقد جاء مركز قضاء النجف بانتاج بلغ (r . rorr

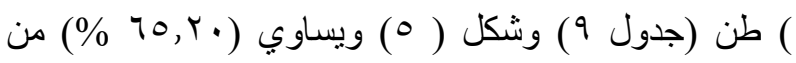

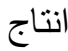

شكل (ع)-المساحة المزروعة لمحصول الشعير لمحافظة

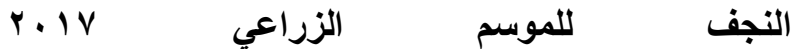

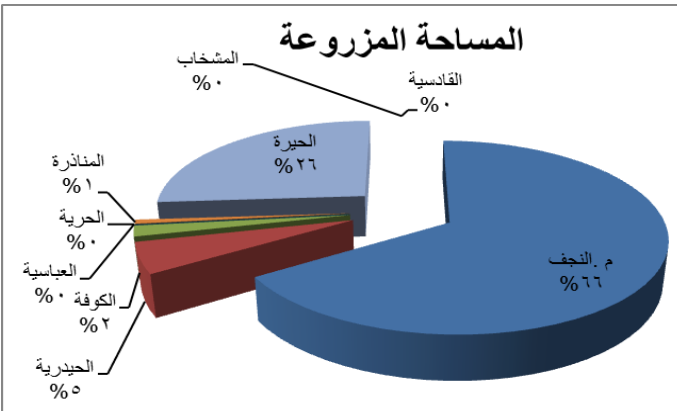

المصدر : من عمل الباحثين بالاعثماد على بيانات جدول 
الدراسة اثبات الفرضية (ملائمة المقومات الطبيعية لزراعة محصولي القمح و الشعيرفي محافظة النجف ) . كما ان هناك امكانية للتوسع في زر اعة القمح والشعير وزيادة انتاجيتهما .

شكل (")-معدل الغلة لمحصول الثعير (كغم ادونم )

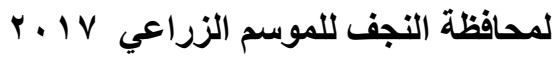

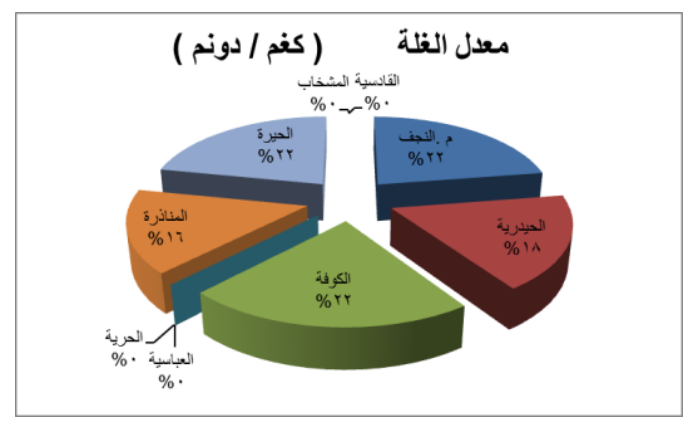

المصدر : من عمل الباحثين بالاعتماد على بيانات جدول

(9)

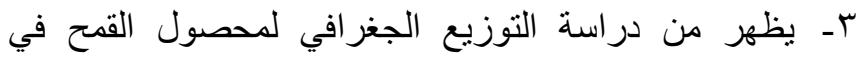

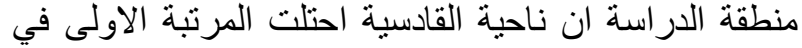

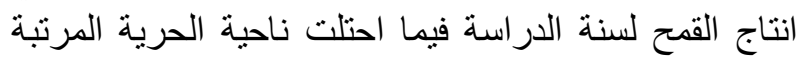
الاخيرة لانتاج هذا المحصول .

ـ - يتبين من دراسة التوزيع الجغر افي لمحصول الشعير في

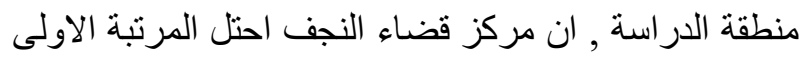
لانتاج الشعير فيما احتلت ناحيتي الحرية و العباسية المر اكز

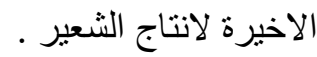

7- عايد جاسم الز املى ,تحليل جغر افى لتباين اشكال

سطح الأرض فى محافظة النجف , رسالة

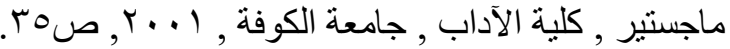

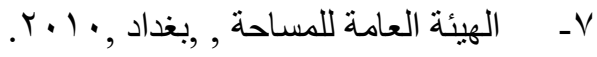

8- Buring ' $p$; Soils and Soil Conditions in Iraq-Nether land،H. Veeman and Zonen N.V; 1960.p151.

صلاح علي حمزة حسن ، المقومات الجغر افية $-9$

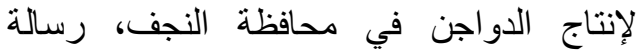

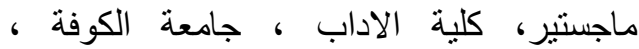

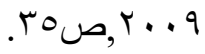

• اـ فلاح حسن شنون ، " دراسة جيمور فولوجية

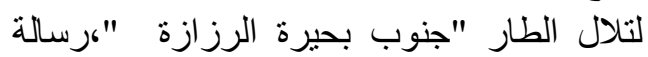

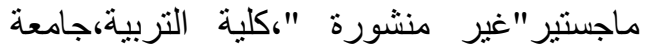

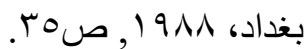
1ا- - علي حسين الثلش , جغرافية التربة , مطبعة

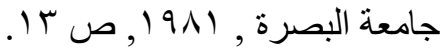

, في حين بلغت انتاجية الدونم في العراق خلال هذا الموسم (

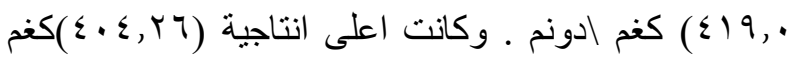
ادونم من نصيب مركز النجف , و و ادناها S كغم|دونم في مركز قضاء المناذرة , اما انتاجية (YN I, V9) الدونم من محصول الثعير في بقية الوحدات الادارية فتنحصر بين الغلتين السابقتين الذكر(جدول 9) , المناطق المتبقية لاتوجد فيها مساحة لزر اعة محصول الثعير ويظهر من جدول (9) ان هناك اربعة وحدت ادارية وهي نواحي لوني (العباسية والحرية والمشخاب) , ويعزى السبب لقلة قيمته المادية من جهة وتفضيل زر اعة محاصيل اخرى من جهة ولهي ثانية , و ايضا لقلة الخبرة في زر اعة هذا المحصول وزر اعة لهن المحاصيل الاكثر انتاجا وربحا (كالرز ) حسب اعتقاد الفلاحيين ـ. و بناء على هذا يتبين ومن خلال تحليل نتائج

\section{- : النتائجج}

1- تاتثر انتاج محصولي القمح والشعير بالعوامل الطبيعية

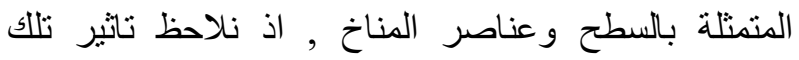
العو امل على انتاجية المحصوليين .

r- نلاحظ في المبحث الرابع تذبذب المياة الواردة الى منطقة

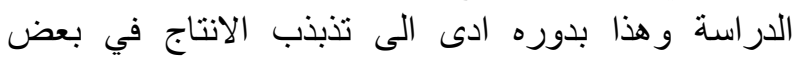

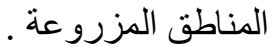

\section{الـهوامش : -}

1- نوري خليل البزازي , ابراهيم عبد الجبار المشهداني , الجغر افية الزراعية , الطبعة الاولى الطي

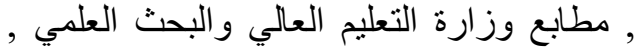

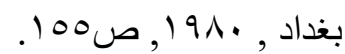
r الجمهورية العربية السورية , شبكة المعرفة www.reefnet.gov.sy. , الريفية

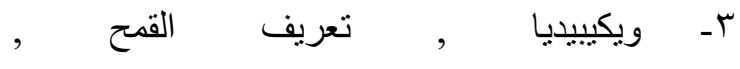
.ar.m.wikipedia.org .

ع - عبد الاله رزوقي كربل , ماجد السيد ولي محمد , علم الطقس والمناخ , جامعة البعة البصرة مطبعة

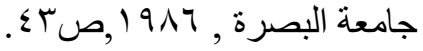

0ـ وزارة التخطيط والانماء ,الجهاز المركزي

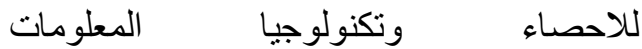

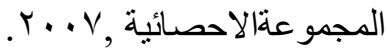




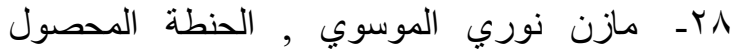

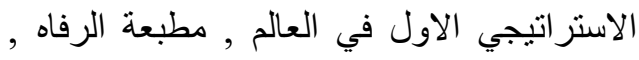

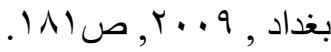

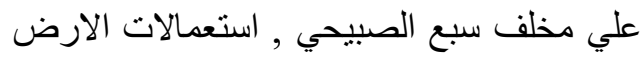
الزراعية في مشروع الاسحاقي , رسالة ماجستير(غير منشورة ) , كلية الاداب , جامعة

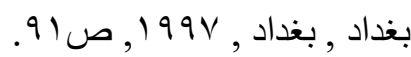

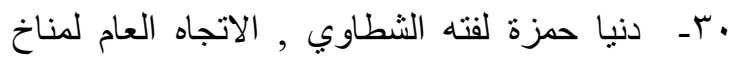

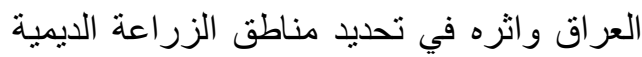

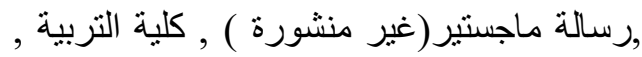

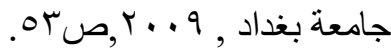

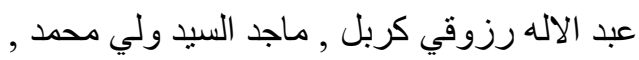

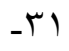

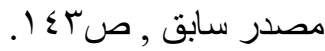

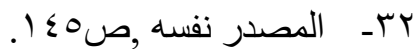
محمود بدر علي السميع , الخصائص الطبيعية

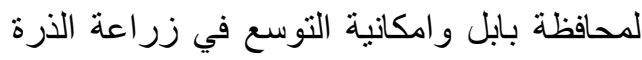
الصفراء , مجلة البحوث الجغر افية , كلية التئ التربية

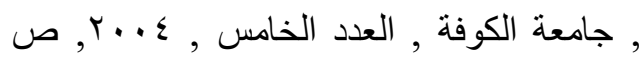

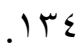
عبد الحميد احمد يونس , انتاج وتحسين المحاصيل الحقلية , جامعة بغداد , دار الكتب

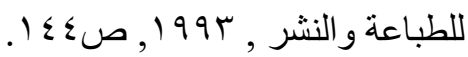
جلال علي حسين , علي عبد الحسين , انتاج

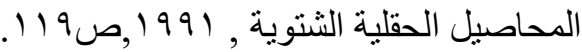

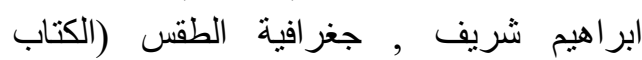
الاول), مطبعة جامعة بغداد ,بغداد , 1910,

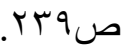

rV السامر ائي , المناخ التطبيقي , دارئ دار الحكمة

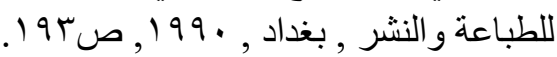

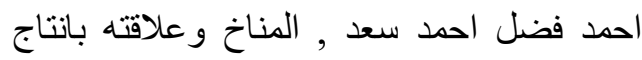
القمح و الذرة الثامية والرفيعة في الجمهورية

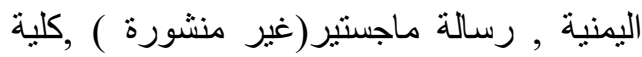

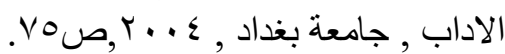
محمد عبد السعيدي , اساسيات انتاج المحاصيل الحقلية , بغداد , ب دار الحرية للطباعة 101 $1919 \mathrm{v}$,

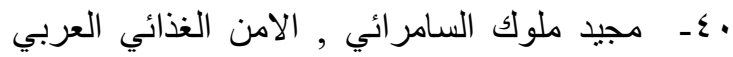

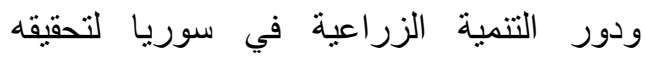
المؤتمر الدولي "التنمية الزية في الزية النية المستدامة

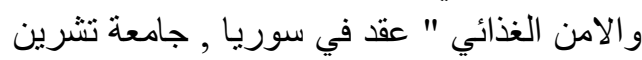

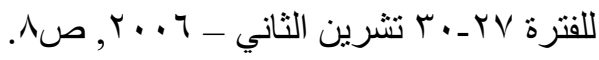

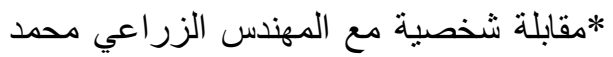
جدو ع , مديرية زر اعة لناحية العباسية , بتاريخ $\left.r \cdot \mid V_{-}\right) 11-1 r$
Y I- ابراهيم شريف , علي حسين الشلش , جغر افية

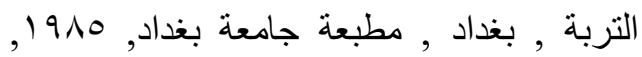

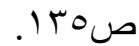
با- شخي فيصل الاسدي ، تحليل جغرافي لانماط

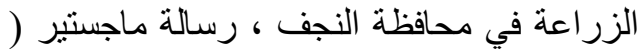

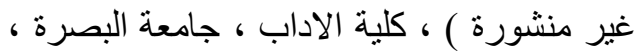
.7V_T7ص, 1911

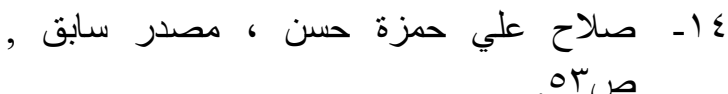

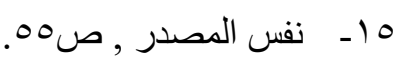

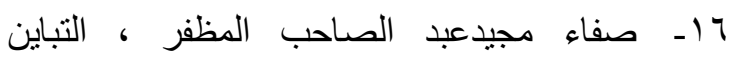

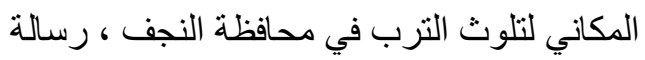

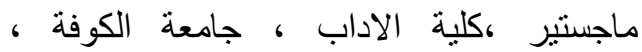
. $\varepsilon V, r \cdots V$ IV

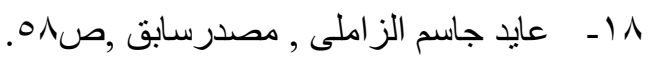

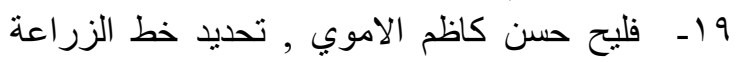

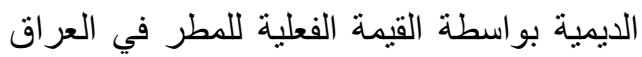

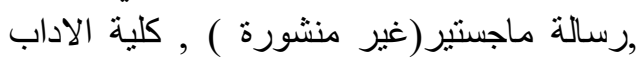

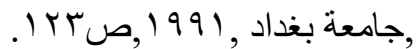

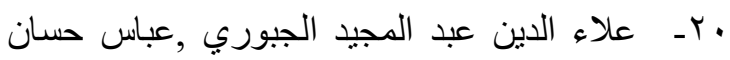
شويليه , انتاج محاصيل الحبوب و البقول اليقول , بغداد

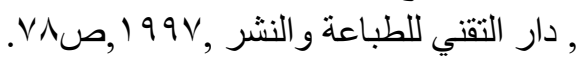
ا Y- محمود عبد القوي زهران , اساسيات علم البيئة

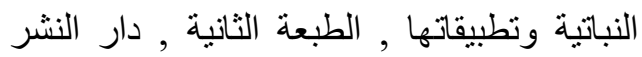

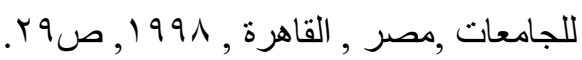

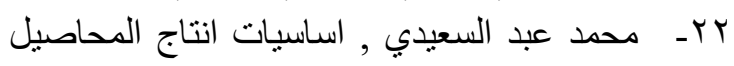
الحقلية , بغداد , دار الحرية للطباعة , 19NV

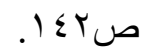

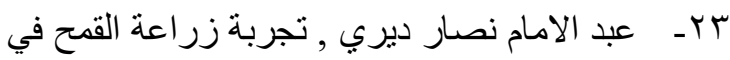

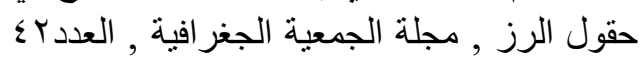

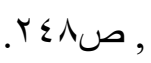
§؟- علي الخشن , احمد انور عبد الباري , انتاج

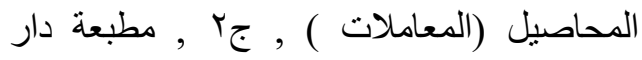

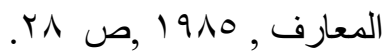

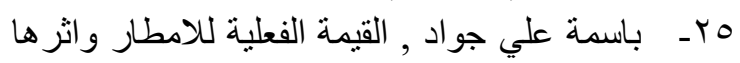

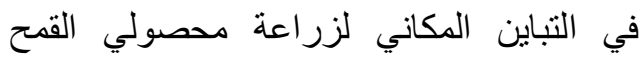

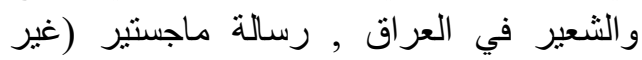
منشورة ) , كلية الاداب , جامعة البصرة , ربالة دم דr- مخلف شلال مرعي , عناصر المناخ المؤثرة في

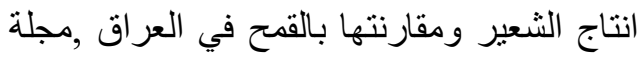

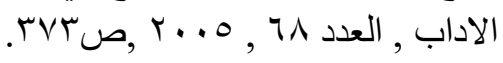

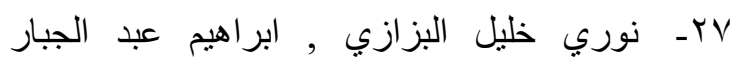

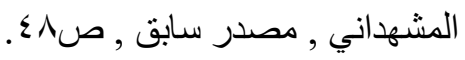




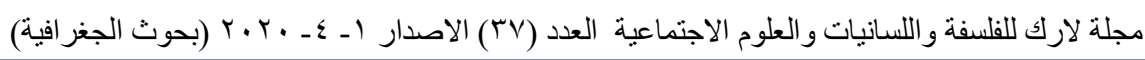

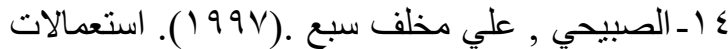

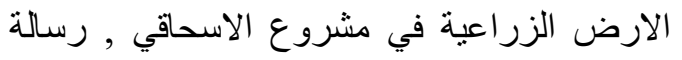

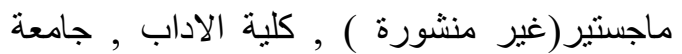

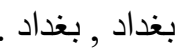

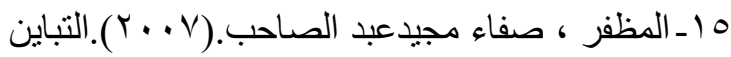

المكاني لتلوث الترب في محافظة النجف ، الناء ، رسالة

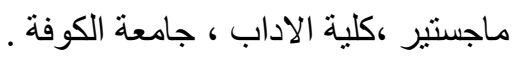

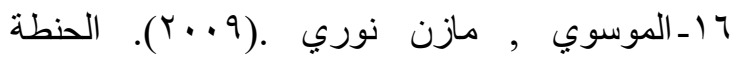

المحصول الاستراتيجي الاول في العالم , مطبعة

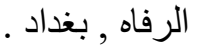

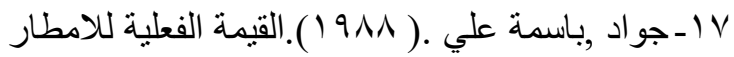

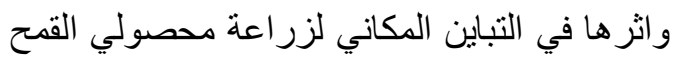

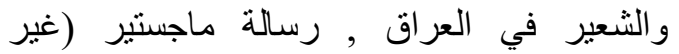

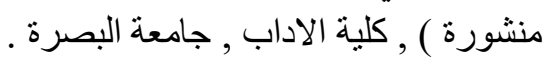

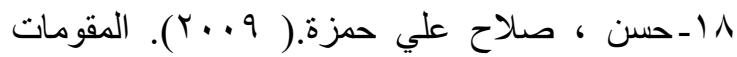

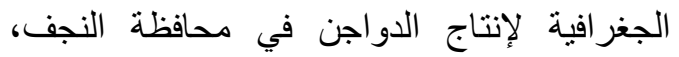

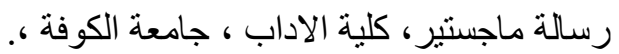

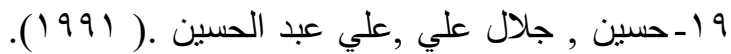

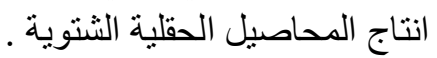

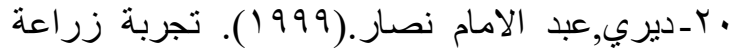

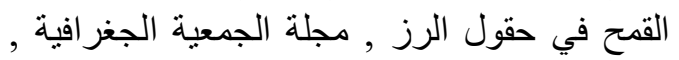

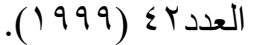

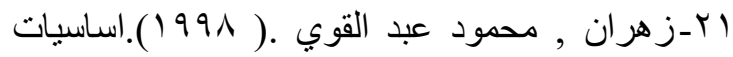
علم البيئة النباتية وتطبيقاتها , الطبعة الثانية , دار النشر للجامعات ,مصر , القاهرة.

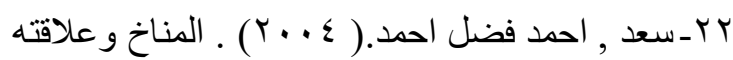
بانتاج القمح و الذرة الثامية و الرفيعة في الجمهورية اليمنية , رسالة ماجستير(غير منشورة ) ,كلية الإنية الاداب , جامعة بغداد

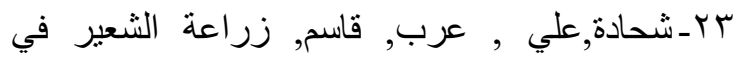
الجمهورية العربية السورية , شبكة المعرفة الريفية www.reefnet.gov.sy. ,

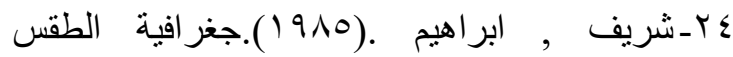

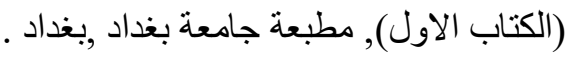

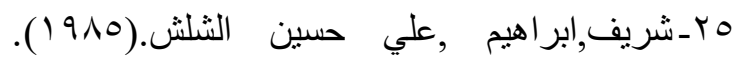

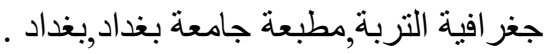

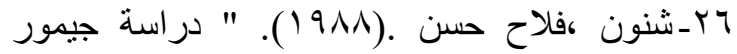

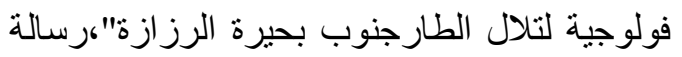
ماجستير"غير منشورة "،كلية التربية،جامعة بغداد الراد

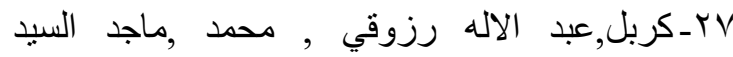
ولي.(7 (911). علم الطقس و المناخ , جامعة البصرة

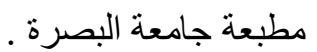

\section{المصادر : المصاد}

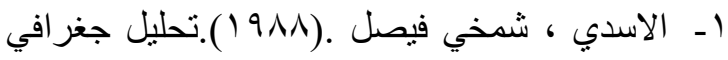

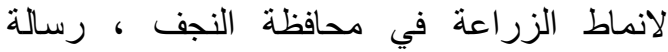
ماجستير ( غير منشورة ) ، كلية الاداب ، جامعة النفة ، رساطة البصرة المهرة

r- الاموي , فليح حسن كاظم (1991 ). تحديد خط

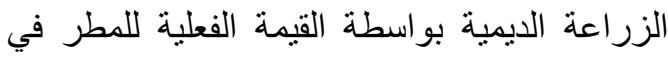

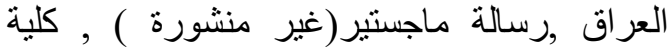

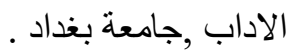

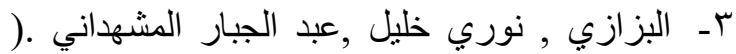

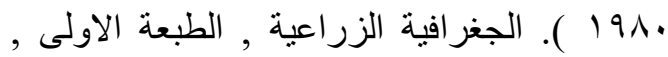

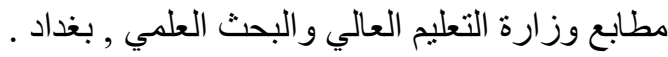
ــ الجبوري ,علاء الدين عبد المجيد ,عباس حسان

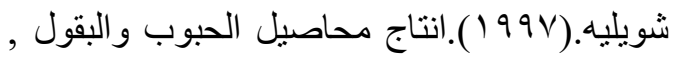
بغداد , دار التقني للطباعة والنشر.

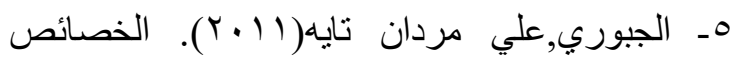
المناخية لمحافظة النجف الاشرف و علاقتتها بالافات الزراعية المؤثرة في انتاج محصول القمح ,رسالة

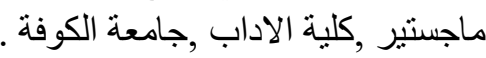

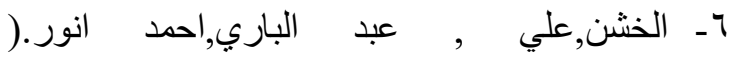

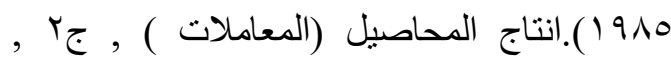

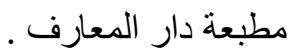

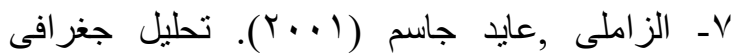

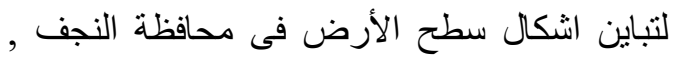
رسالة ماجستير , كلية الآداب , جامعة الكوفة .

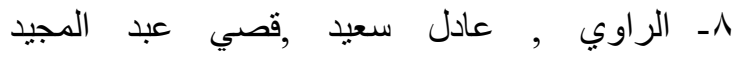
السامر ائي(· • (199).المناخ النطبيقي , دار الحكمة

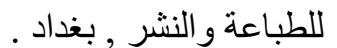

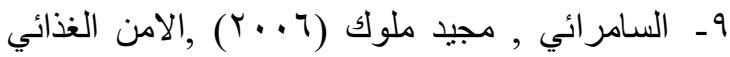
العربي ودور التنمية الزراعية في سوريا لتحقيقه

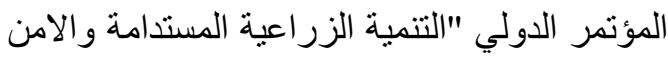
الغذائي " عقد في سوريا , جامعة تشرين للفترة

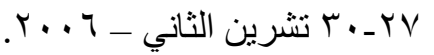

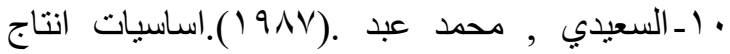

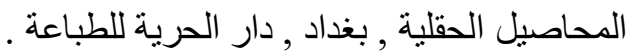

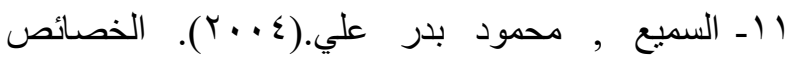
الطبيعية لمحافظة بابل وامكانية التوسع في زر اعة الذبة الذرة

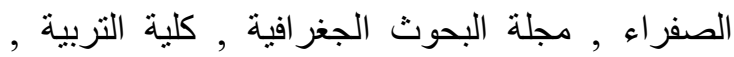
جامعة الكوفة , العدد الخامس .

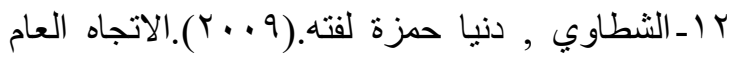

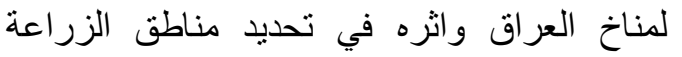
الديمية , رسالة ماجستير(غير منشورة ) , كلية التربية , جامعة بغداد.

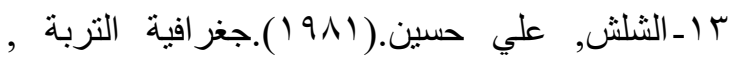
مطبعة جامعة البصرة . 


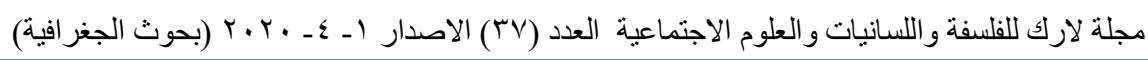

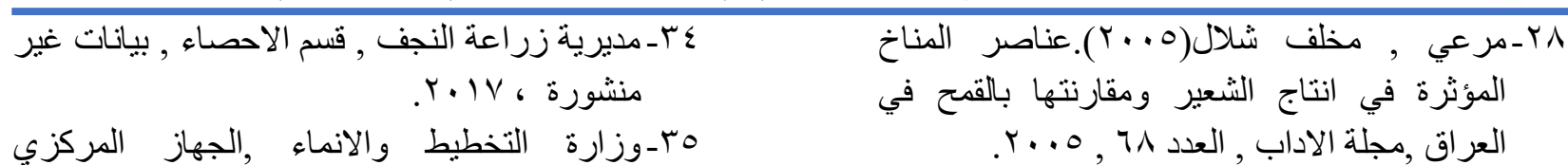

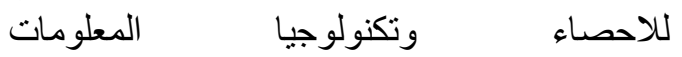

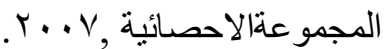

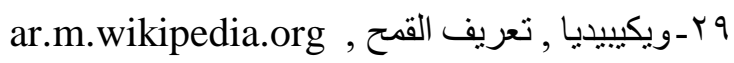

جr-وزارة النقل ، الهيأة العامة للأنواء الجوية و الرصد الرصد

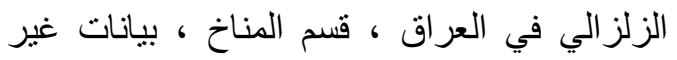

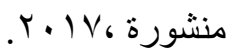

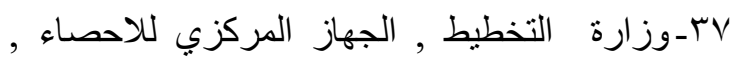

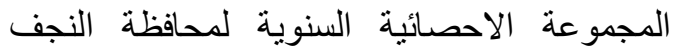

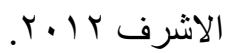

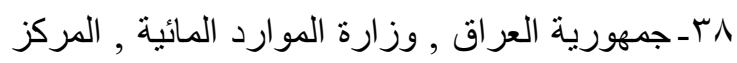

الوطني لادارة الموارد المائية , بيانات غير منشورة الماتية

$$
r \cdot 11,
$$

q ــ مديرية الموارد المائية في محافظة النجف , سجل

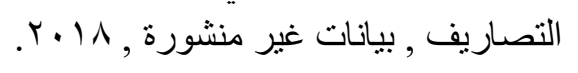

4- Buring 'p; Soils and Soil Conditions in

Iraq-Nether land‘H. Veeman and Zonen N.V;

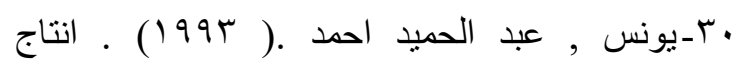

وتحسين المحاصيل الحقلية , جامعة بغداد , دار

$$
\text { الكتب للطباعة و النشر. }
$$

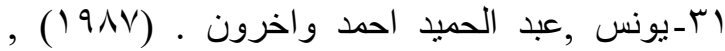

محاصيل الحبوب , وزارة التعليم العالي والبحث البث

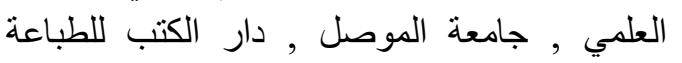

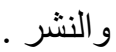

بــ المنشاة العامة للمساحة، بغداد، خريطة العراق

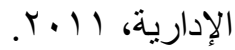

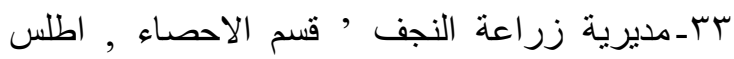

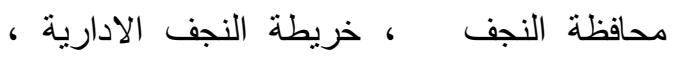
$r+1 r$

1960. 